\title{
A big picture: bibliometric study of academic publications from post-Soviet countries
}

\author{
Maia Chankseliani ${ }^{1}$ (D) Andrey Lovakov ${ }^{2}$ (D) $\cdot$ Vladimir Pislyakov $^{3}$ (D)
}

Received: 10 April 2021 / Accepted: 26 July 2021 / Published online: 18 August 2021

(c) The Author(s) 2021

\begin{abstract}
The world's largest community of scientists disintegrated following the dissolution of the Soviet Union. With extremely scarce resources and limited academic freedom as starting points, researchers in this region have been creating new knowledge; they have been building on rich scientific traditions in selected disciplines and, at times, paving new paths in non-traditional disciplines. At present, the cumulative contribution of post-Soviet countries to global research output is only three percent, indicating that these countries are not key players on the global research scene. This study uses bibliometric methods to offer novel empirical insight into the quantity and impact of academic publications; it also looks at the quality of journals in which the output is published. The findings reveal that fifteen postSoviet countries differ considerably in terms of how much they have prioritised research, as well as the quantity, quality, and impact of their publications. The research productivity across the region has not been high and, taken together, these countries have produced publications of considerably lower quality and lower impact when viewed in the context of global research output. At the same time, researchers from post-Soviet countries tap into international collaborative networks actively, resulting in an exceptionally large proportion of publications from this region being internationally co-authored. In the historical context of Soviet research being known as one of the least collaborative globally, this finding indicates that researchers in the region are attractive to international collaborators and may be seeking such partnerships due to relatively modest research capacity at home.
\end{abstract}

Keywords Bibliometric analysis · Research output - Research impact · Quality of journals · Post-Soviet countries $\cdot$ International collaborations $\cdot$ Mega-collaborations

Maia Chankseliani

maia.chankseliani@education.ox.ac.uk

Andrey Lovakov

lovakov@hse.ru

Vladimir Pislyakov

pislyakov@hse.ru

1 Department of Education, University of Oxford, 15 Norham Gardens, Oxford OX26PY, UK

2 Center for Institutional Studies, HSE University, 11 Pokrovsky Boulevard, Moscow, Russia 109028

3 Library, HSE University, 11 Pokrovsky Boulevard, Moscow, Russia 109028 


\section{Introduction}

The world's largest community of scientists disintegrated in the period following the dissolution of the Soviet Union. The Soviet Union was the first country to build an atomic power plant, to launch the artificial satellite, and to send the first human into space. The Soviet research community was uniform and centralised, highly politicised, and entirely state-driven. As the Soviet system broke down in the early 1990s, a minority of constituent republics started exploring the possibilities of establishing their own, new structures and practices of research. Three decades later, some of the former Soviet countries have not yet charted their research and development (R\&D) strategies. Research achievements from this part of the world rarely make it into international news. Yet, researchers at universities, research institutes, and industrial research centres in post-Soviet countries have not stood still. There exists only a small number of published studies about post-Soviet period covering either selected countries or regions, such as studies examining the research output from the Baltic countries (Allik, 2008, 2015; Hirv, 2019; Kristapsons et al., 2003; Lauk \& Allik, 2018; Zavadskas et al., 2011), Russia (Kirchik et al., 2012; Markusova et al., 2009; Moed et al., 2018; Moskaleva et al., 2018; Pislyakov \& Shukshina, 2014; Wilson \& Markusova, 2004; Yegorov, 2009), post-Socialist Eastern Europe (Kozak et al., 2015), the Caucasus (Gzoyan et al., 2015), and Central Asia (Adambekov et al., 2016; Yessirkepov et al., 2015). A recent paper uses bibliometric analysis to compare the productivity of Russian researchers with those from other post-Soviet countries (Alimova \& Brumshteyn, 2020). A number of publications analyze research output from post-Soviet countries in selected fields of studies, such as modern composite materials (Dickenson, 1996), computer science (Fiala \& Willett, 2015), nanotechnology (Karaulova et al., 2016; Terekhov, 2017), psychology (Lovakov \& Agadullina, 2019), and higher education research (Lovakov and Yudkevich 2021). With limited academic freedom and extremely scarce resources as starting points, researchers in post-Soviet countries continued to create new knowledge; they have been building on well-established scientific traditions while at times paving new paths in nontraditional disciplines in social sciences (Temkina \& Zdravomyslova, 2003; Weinberg, 2017).

The former Soviet countries had a number of common characteristics in the early 1990s. The Soviet Union was a world leader in selected disciplines such as physics and mathematics; it also had a strong scientific tradition in oceanography, seismology, metallurgy, magnetohydrodynamics, and chemical catalysis (Graham, 1992). The advancements in atomic weapons development and space technology, the so-called "big technology", were explained by the unprecedented level of centralised government control of personnel and resources which allowed the Soviet government to focus on selected high-priority projects (Graham, 1992). Most of the large research projects were concentrated in the urban centres of the Russian SFSR such as Moscow, Saint-Petersburg, and Novosibirsk as well as Kiev in the Ukrainian SSR. The Russian Federation subsequently became the legal heir of the Soviet Union, inheriting a large portion of the Soviet scientific infrastructure (Schneider, 2013). The bulk of the Soviet scientific activity was carried out at research institutes, affiliated with the Soviet or republican Academies of Science or sectoral ministries. Higher education institutions had a minor role in research, employing only one third of the R\&D personnel (USSR, 1988).

Similar to other countries where the "collaborative imperative" dominated the hard disciplines (Kyvik \& Larsen, 1997; Lewis, 2013), the military and space research projects in the Soviet Union were undertaken by large teams of scientists (Kojevnikov, 2002). In 
disciplines such as physics or medicine/epidemiology, mega-collaborations prevailed. Then and now, mega-collaborations have been a common practice in many countries. Normally, publications with large numbers of authors tend to be more cited and the impact of such publications can greatly affect the overall bibliometric indicators for countries, especially if the country has a small total number of publications (Aksnes \& Sivertsen, 2004; Hirv, 2019; Potter et al., 2020). In contrast, "the lonely scholar" model remains prevalent in humanities and to a certain extent in social sciences (Kwiek, 2017; Lewis et al., 2012). Mega-collaborations normally involve researchers from multiple countries. The Soviet mega-collaborations were different in this respect.

A key characteristic of Soviet research was its seven-decade-long isolation from international influence. Soviet citizens were seldom allowed to travel abroad (Matthews, 2011). Hence, opportunities for international collaborations were extremely limited (Kozak et al., 2015). By and large, research collaborations in the Soviet Union were domestic and the USSR was recognised as one of the least collaborative countries globally (Schubert \& Braun, 1990). The dissolution of the Soviet Union led to the opening of borders in most of the former Soviet countries. Yet, building research collaborations from scratch was not straightforward, considering the researchers' limited experience of international collaborations, the language barrier, scarce resources available for establishing such collaborations, and the limited knowledge of the global state-of-the-art developments in respective disciplines.

Following the dissolution of the Soviet Union, 15 countries chose divergent paths of economic, social, and political development (Chankseliani, 2018; Chankseliani \& Silova, 2018a). Higher education and research policy discourses across post-Soviet countries emphasise global norms, global reputation, and global competitiveness (Chankseliani \& Silova, 2018b). Global is becoming a condition in which individuals, institutions, and countries aspire to act. Yet, the investments in R\&D are not aligned with the aspirations. The Gross Domestic Expenditure on R\&D (GERD) ranges between 0.10 and $0.13 \%$ of GDP in Tajikistan, Kyrgyzstan, Kazakhstan, and Uzbekistan (Table 1). In contrast, Belarus, Latvia, Lithuania, and Russia allocate between 0.61 and $0.99 \%$ to R\&D. Azerbaijan, Armenia, Moldova, Georgia, and Ukraine spend between 0.18 and $0.47 \%$ of their GDP on R\&D. Estonia spends the largest proportion of its GDP-1.43\%—on R\&D. In contrast, the Soviet Union spent far more-6\% of Gross Domestic Income-on science (USSR, 1988).

Considering the substantial differences in these countries' GDP per capita and the population numbers, the variation in the GERD as a percentage of GDP translates into vast differences in the GERD per capita (Table 1). ${ }^{1}$ Tajikistan, Kyrgyzstan and Uzbekistan spend $\$ 3$ to $\$ 9$ per capita on R\&D. In Moldova, Armenia, Georgia, Azerbaijan, Kazakhstan, and Ukraine, the GERD per capita ranges between \$19 and \$44. Russia (\$275) spends more than twice as much as Belarus (\$121). Finally, the three Baltic States differ significantly in their per capita investment in R\&D, with Latvia spending \$193, Lithuania—\$333, and Estonia-\$504.

Academic publishing is a fundamental domain of R\&D systems and knowledge production as it helps with the formation and maintenance of disciplines and knowledge networks (Collyer, 2018). As new incentive and reward systems are being introduced, and research

\footnotetext{
${ }^{1}$ The UNESCO Institute of Statistics defines GERD per capita as the "total intramural expenditure on R\&D performed during a specific reference period per inhabitant" (UIS 2020a). Intramural R\&D expenditures are defined as all current and gross fixed capital expenditures for R\&D, irrespective of the source of funds (UIS 2020b).
} 


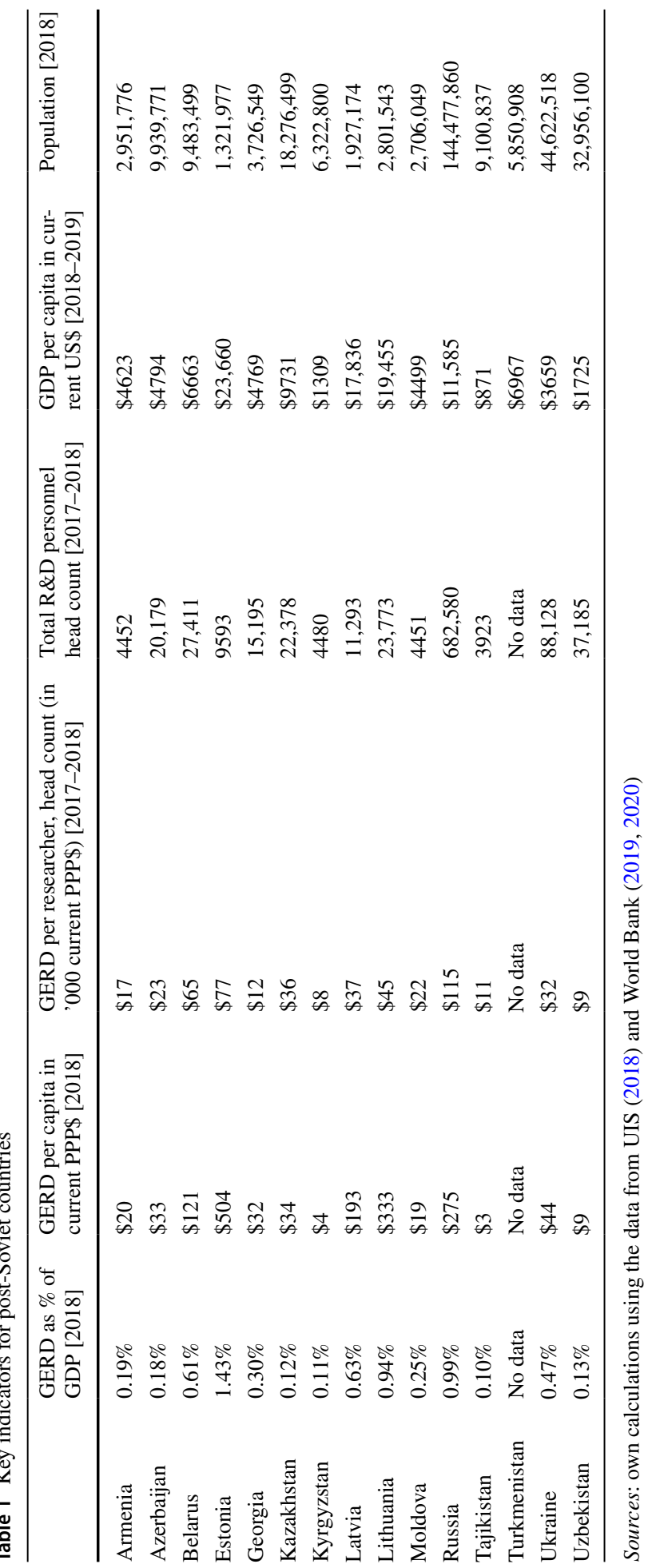


governance is becoming more output-oriented, the policy relevance of understanding the latest trends and dynamics in the production of research output has been increasing. At the same time, the research on research has been extremely scarce which means that there exists very limited scholarly evidence on knowledge production in post-Soviet countries. This study represents the first attempt of offering a big picture analysis of the quantity, quality, and impact of academic publications by area of study, by authorship, and by country. In order to position the research output from this region in the global context, the study is limited to the analysis of what we refer to as the global domain of research output from post-Soviet countries.

\section{Data and methods}

Bibliometric indicators are widely used in the evaluation of research output by governments, university administrators, and researchers. At the same time, the institutionalisation of international databases has supported the development of new knowledge on global science (Gingras, 2016; Kwiek, 2020; Martinez \& Sá, 2020; Muller, 2018). The present study contributes to this body of knowledge and uses the Web of Science (WoS) as the source of the bibliometric data. The WoS is a publisher-independent global database. The composition of journals indexed in WoS is selective and relatively stable over time which makes it possible to analyse the dynamics of output and impact reliably (Moed et al., 2018). For the purposes of this study, the WoS data was complemented with some macro-level indicators from the UNESCO Institute of Statistics and the World Bank.

The bibliometric analysis was performed using InCites, an analytical tool which contains a number of bibliometric indicators aggregated from WoS countries, organizations, and researchers. We analysed publications in journals indexed in three widely used journal citation indexes: Science Citation Index Expanded (SCIE), Social Sciences Citation Index (SSCI), and Arts \& Humanities Citation Index (A\&HCI). The stability and reliability over time are the reasons why this study does not include publications in journals indexed in the Web of Science Emerging Science Citation Index. The WoS database was accessed from the National Research University Higher School of Economics Library and last updated in August 2020.

The analysis includes all Articles and Reviews published in English and non-English languages, such as Russian, Lithuanian, Ukrainian, and Estonian. English is the language of global science, and the majority of the national journals from post-Soviet countries included in the WoS are either published in English or have English versions. There were $1,100,775$ publications analysed. We used 200 publications as an analytical minimum for citation-based indicators. Each of the 15 countries had more than 200 publications for the period $1993-2019$. When we report on a single year or a portion of publications, we use an asterisk to denote that the specific citation-based indicator refers to fewer than 200 publications.

The analysis covers the period of 1993-2019. Despite the fact that the constituent republics of the USSR gained independence in 1991, the WoS output from 1991 and 1992 was "transitional", i.e. the author affiliations in the output do not clearly differentiate among the USSR, the newly independent states, the Russian SFSR, and Russia. Starting from 1993, the data identifies the authors' countries of affiliation much more precisely. A publication was attributed to the country according to authors' affiliations. For example, if the country of at least one institutional affiliation of the publication's author was Armenia, 
then the publication was considered as Armenian. For internationally co-authored publications we used the whole counting method. If the authors of the publication had affiliations with several post-Soviet countries, the same publication was attributed to each of these countries.

To analyse the subject structure of research output, the study used the OECD category scheme which divides all journals into six major areas of study: Natural Sciences, Engineering \& Technology, Medical \& Health Sciences, Agricultural Sciences, Social Sciences, and Humanities (OECD, 2007). The use of the journal category for classifying the output by area of study led to a certain overlap in the attribution of output published in cross-disciplinary journals; this fully accounts for the contributions of output to more than one area of study.

As the indicator of the quality of the research output, this study uses the WoS quartile ranking of the journals where the research is published. Journals indexed in the WoS are divided into Quartile 1, Quartile 2, Quartile 3, and Quartile 4, based on the journal impact factor. The quality decreases as we move from Q1 to Q4. For journals indexed in A\&HCI, the impact factor is not calculated, as impact factor is considered to be a poor reflection of quality in Arts and Humanities. The WoS does not provide quartile attribution for the A\&HCI journals as quartiles are based on the impact factor.

As the indicator of impact of the research output, this study uses the number of times each publication is cited. Citations are considered to represent the impact of academic publications and are widely used in the analysis of academic output and research evaluation. The following two indicators of impact are included in the analysis: Category Normalized Citation Impact (CNCI) and the proportion of publications in the Top 10\% of the most cited publications in the InCites database. Both indicators are normalized by WoS subject category, year of publication, and publication type.

While the indicators of impact and quality rest on the same measure - the citations, one pertains to the publication itself (impact) and another the journal (quality). Two indicators of impact (CNCI and Top10\%) are based on the number of citations of a publication which takes time to accumulate. The indicator of journal quality pertains to the average number of citations received by papers in the journal in which the paper is published. Thus, while the impact indicator pertains to the citations accrued to each publication included in this analysis, the quality indication pertains to the journals in which publications included in this analysis are published, and is a sign of meeting specific standards of quality, expressed by the journal impact factor.

The use of WoS data for the analysis of the research output from post-Soviet countries is not without limitations. The database has problems with the coverage of Humanities and Social Sciences publications and the coverage of publications in languages other than English (Aksnes \& Sivertsen, 2019). The use of this database underestimates publications in these areas. National journals are published in a number of post-Soviet countries. According to Master Journal List (June 2021), Russia has 161 national journals indexed in the SCIE, SSCI, and AHCI indexes of the WoS, Lithuania-26, Ukraine and Estonia-11 each, Latvia-4, Azerbaijan-2. Armenia, Belarus, Georgia, and Uzbekistan have one journal each indexed in Scopus. Kazakhstan, Kyrgyzstan, Moldova, Tajikistan, and Turkmenistan have no national journals in Scopus. Thus, only a small minority of national journals are indexed in WoS which means that this study does not include the publications from the majority of national journals publishing in English or vernacular languages, such as Russian (Brumshteyna \& Alimova, 2019). Globally, considerably larger shares of the WoS publications in Arts \& Humanities are published in non-English languages, when compared to approximately five percent of non-English language publications in SCI and 
Table 2 Number of articles and reviews by country, $1993-2019$

\begin{tabular}{ll}
\hline Country & $\begin{array}{l}\text { Number of } \\
\text { articles and } \\
\text { reviews }\end{array}$ \\
\hline Armenia & 14,150 \\
Azerbaijan & 9658 \\
Belarus & 30,048 \\
Estonia & 31,791 \\
Georgia & 11,267 \\
Kazakhstan & 12,027 \\
Kyrgyzstan & 1948 \\
Latvia & 13,901 \\
Lithuania & 38,281 \\
Moldova & 6005 \\
Russia & 800,135 \\
Tajikistan & 1500 \\
Turkmenistan & 290 \\
Ukraine & 120,701 \\
Uzbekistan & 9073 \\
\hline
\end{tabular}

SSCI (Liu, 2017). Publications in languages other than English have lower citation counts (Liu, 2017). Therefore, the WoS data is expected to underestimate the quality and impact of research output from post-Soviet countries, especially in the area of Art \& Humanities.

\section{Results}

\section{Quantity}

At the time of the dissolution of the Soviet Union, the research output produced in this vast country constituted $4.6 \%$ of the total global research output. After two decades of independence, the cumulative research output from post-Soviet countries had dropped to $2.7 \%$ (2012) of the total global research output. This proportion started a slow rise in 2014 and in 2019 reached $3.0 \%(58,944$ publications $)$ of the total global output. Out of the cumulative regional contribution, $76 \%$ (45,052 publications) are (co-)authored by researchers in Russia and $8 \%(4,964)$ by researchers in Ukraine. These are followed by Lithuania $(3,260)$, Estonia (2,629), Kazakhstan $(1,664)$, Belarus $(1,442)$, Latvia $(1,155)$, and Armenia $(1,028)$ with a four-digit research output in 2019. There have been relatively smaller numbers of publications emerging from Azerbaijan (922), Georgia (873), Uzbekistan (430), Moldova (297), Kyrgyzstan (233), Tajikistan (143). Turkmenistan had only five WoS publications included in 2019. The cumulative numbers for 1993 to 2019 are provided in Table 2.

When comparing the research output in 2019 to the research output in 1993, large differences are observed by country (Fig. 1). Lithuania is the leader with $1522 \%$ increase in the research output. It is followed by Estonia (842\%), Kazakhstan (582\%), Kyrgyzstan (513\%), Armenia (397\%), Azerbaijan (361\%), Latvia (336\%), and Georgia (316\%). The growth statistics in Russia, Tajikistan, Moldova, Belarus, Ukraine, and Uzbekistan are relatively modest. Turkmenistan had fewer publications in 2019 than in 1993. The countries with 


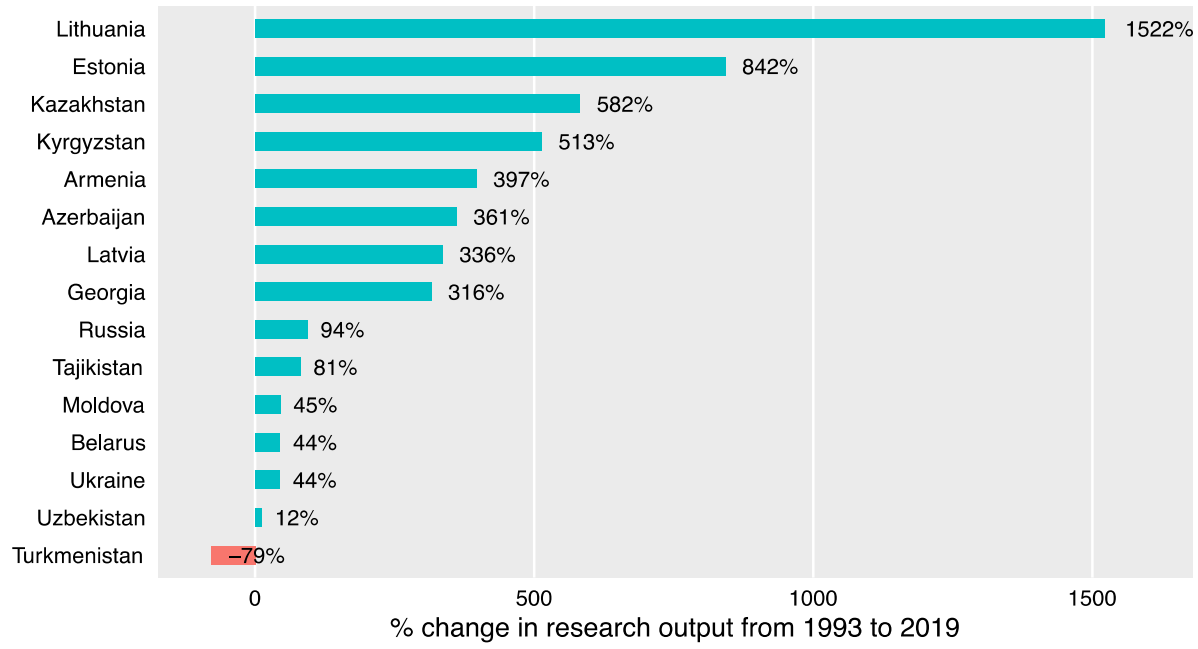

Fig. 1 Research output in 2019, expressed as a proportion of research output in 1993

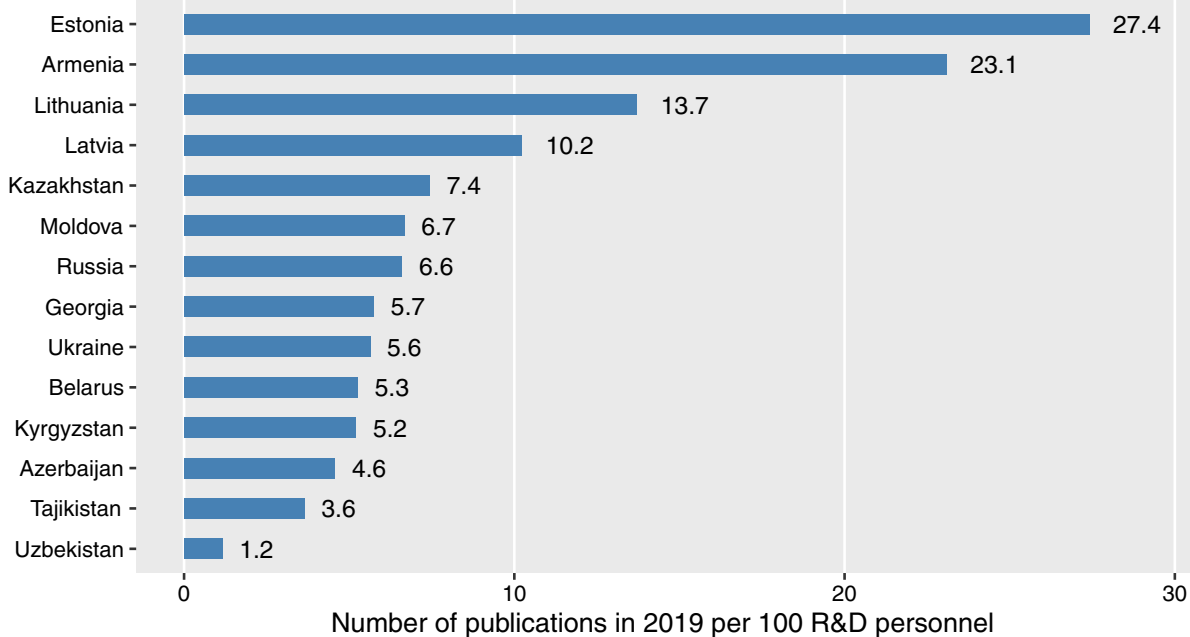

Fig. 2 Number of publications in WoS per R\&D personnel (HC). Note: own calculations based on the WoS (2019) and UIS data (2018). Turkmenistan data is not available

larger overall increases in the output (the top half of Fig. 1) appear to have achieved the growth through a more or less steady annual expansion of their research output (Fig. 12). The only exception is Kazakhstan. The number of publications in Kazakhstan was mostly flat between 1993 and 2012. In 2012, the number of Kazakhstani publications started a steep climb and increased threefold within six years.

In a number of post-Soviet countries, universities have become key producers of global knowledge. In Georgia, Kazakhstan, Estonia, Lithuania, and Latvia, more than $80 \%$ of all publications have a university-based author. More than half of all publications from Russia, 

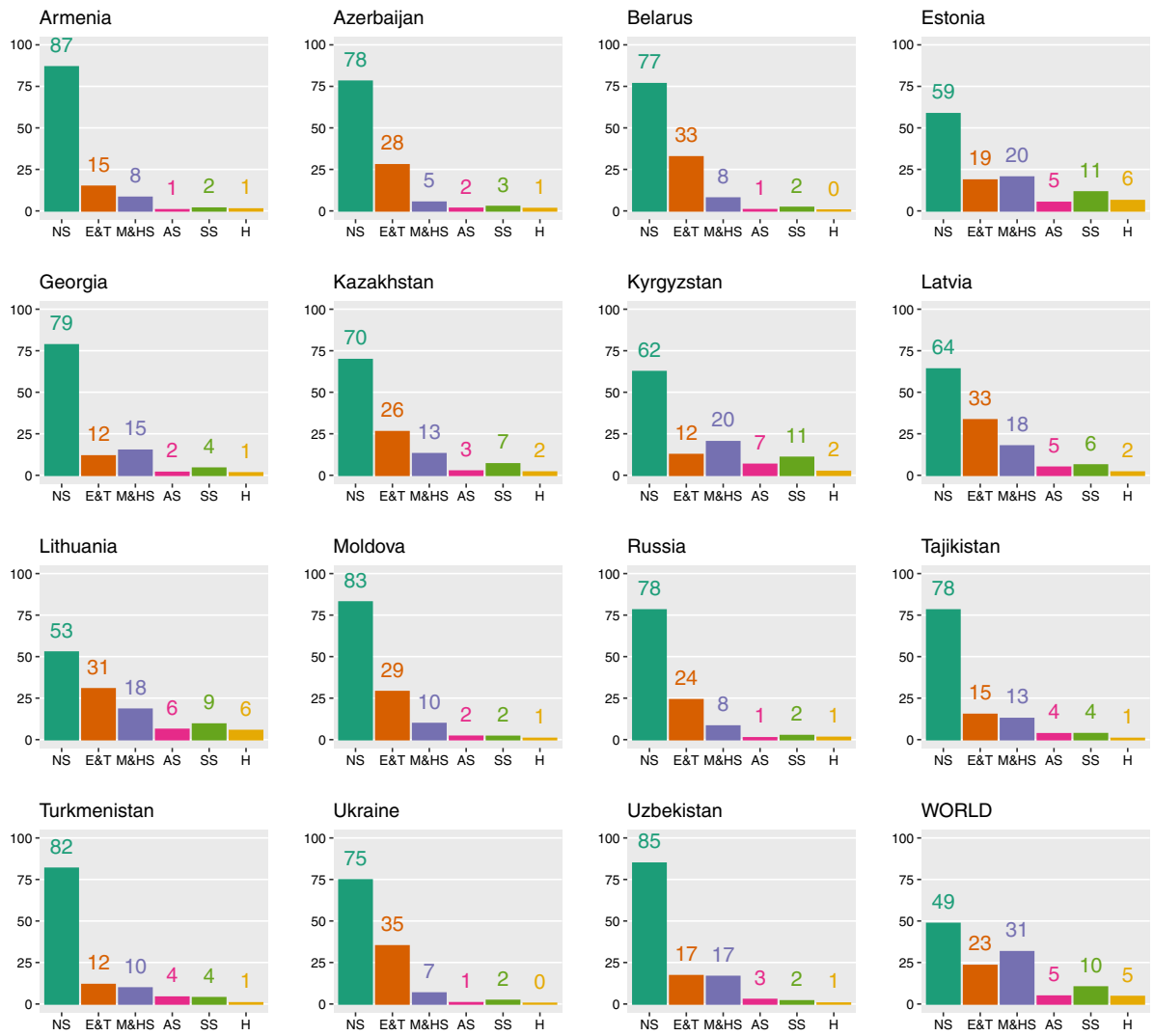

NS $\square$ E\&T $\square$ M\&HS $\square$ AS $\square$ SS $\square$ H

Fig. 3 Distribution (\%) of publications by area of study (1993-2019). Notes: a NS Natural sciences, E\&T Engineering \& technology, $M \& H S$ Medical \& health sciences, $A S$ Agricultural sciences, $S S$ Social sciences, $H$ Humanities; b the use of the journal category for classifying the output by area of study led to a certain overlap in the attribution of output published in cross-disciplinary journals. This figure fully accounts for the contributions of output to more than one area of study

Belarus, Turkmenistan, Ukraine, and Kyrgyzstan have a university-based author. Between 40 and $50 \%$ of publications from Uzbekistan, Moldova, Azerbaijan, and Tajikistan are authored by university-based academics. Armenia has the lowest proportion of publications $(36 \%)$ with at least one university-based author.

The research productivity, as measured by the number of publications per R\&D personnel, is low across all countries (Fig. 2). In Uzbekistan, every 100 R\&D personnel produced one publication in 2019. This is followed by Tajikistan with four publications per 100 researchers. Azerbaijan, Kyrgyzstan, Belarus, Ukraine, Georgia, Russia, Moldova, and Kazakhstan have between five and seven publications per 100 R\&D personnel. Lithuania, Armenia, and Estonia represent relatively more productive systems with the productivity ranging between 10 and 27 publications per 100 researchers.

The countries with larger GERD per researcher have higher numbers of R\&D personnel and tend to produce more publications. The GERD per researcher is positively correlated 
with the overall number of countries' publications (Pearson's product-moment correlation $r=0.77, p=0.001$ ). As seen in Table 1 , countries that prioritize $\mathrm{R} \& \mathrm{D}$ and have higher GERD as a percentage of GDP, tend to have larger GERD per researcher.

When it comes to the analysis of the output by area of study, Natural Sciences dominate the publications from post-Soviet countries (Fig. 3). The explicit interest in Natural Sciences in this region is most likely due to rich scientific traditions in a number of Natural Science disciplines. The proportion of publications classified as Natural Sciences ranges between $53 \%$ of all publications in Lithuania to $87 \%$ in Armenia. More than four in five publications in Uzbekistan, Moldova, and Turkmenistan have been in Natural Sciences. While Natural Sciences is the single most prominent area of study in which post-Soviet countries feature on the global stage, in the last two decades, the proportion of Natural Sciences output has decreased in almost all post-Soviet countries (Fig. 2). The largest drops in the proportion of Natural Sciences publications are observed in Moldova, Lithuania, and Kazakhstan (Fig. 13).

The share of the Engineering \& Technology output from post-Soviet countries (22\%) is close to the global share (23\%) of Engineering \& Technology publications. Notably, Ukraine, Belarus, Latvia, Lithuania have significantly higher proportions of Engineering $\&$ Technology publications when compared to the global share; in these countries almost one in three publications are in Engineering \& Technology. In contrast, only one in ten publications from Turkmenistan, Kyrgyzstan, and Georgia are in Engineering \& Technology (Fig. 3). In the last two decades, Engineering \& Technology has seen the largest $(8 \%)$ increase across all areas of studies globally. Kazakhstan, Moldova, and Tajikistan had increases higher than the world average. The majority of the former Soviet countries saw a decrease in the share of their Engineering \& Technology output since 1998, with the largest drops observed in Armenia and Azerbaijan (Fig. 13).

Unlike Natural Sciences and Engineering \& Technology, the proportions of publications in Humanities, Social Sciences, Agricultural Sciences, and Medical \& Health Sciences are significantly below the proportions in the respective areas of studies globally (Fig. 3).

The Humanities publications constitute about $1 \%$ or less of the total publications for 10 out of 15 countries (Fig. 3). Only Estonia and Lithuania (6\%) have a slightly higher proportion of Humanities publications, when compared to the share of the Humanities publications globally (5\%). In the last two decades, the proportion of publications in Humanities has been rising slowly but steadily across most post-Soviet countries (where data is available), with Estonia and Lithuania showing the largest increases (four to six percentage points, Fig. 13).

In Social Sciences, Armenia, Uzbekistan, Moldova, Belarus, Ukraine, Russia, and Azerbaijan have particularly small proportions (less than 3\%) of publications, as a share of the country's research output (Fig. 3). Only two countries-Estonia (11\%) and Kyrgyzstan (11\%) - have slightly higher shares of Social Sciences publications when compared to the share of Social Sciences publications globally (10\%). In the last two decades, the proportion of Social Sciences output has been rising in all countries with particularly large increases in Lithuania, Estonia, Kyrgyzstan, and Georgia (Fig. 13). In the same period, the smallest increases in the Social Sciences output are observed in Russia, Ukraine, and Armenia. Belarus is the single country where we see a decrease in the proportion of publications in Social Sciences.

The share of publications in Medical \& Health Sciences ranges from 5\% of all publications in Azerbaijan to $20 \%$ in Estonia and Kyrgyzstan. Globally, the share of M\&HS publications is $31 \%$ (Fig. 3). In the last two decades, the post-Soviet countries have seen an increase of their Medical \& Health Sciences research output in contrast to the global 


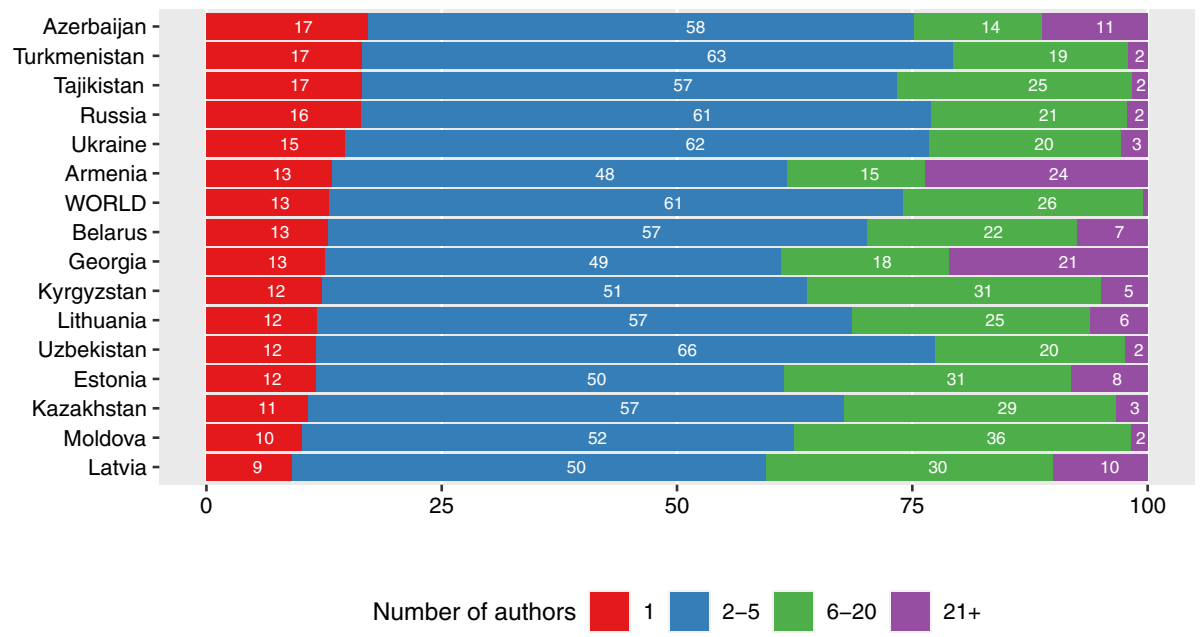

Fig. 4 Proportions of publications with different number of authors (1993-2019)

decrease by two percentage points (Fig. 13). The largest increase is seen in Moldova and Kyrgyzstan, followed by Tajikistan, Uzbekistan, Lithuania, Latvia, Georgia, and Kazakhstan.

Finally, in Agricultural Sciences, all post- Soviet countries except Kyrgyzstan, Lithuania, and Estonia produce considerably lower proportions of publications when compared to the 5\% share of Agricultural Sciences publications globally (Fig. 3). Armenia, Belarus, and Ukraine have particularly low proportions of Agricultural research. In the last two decades, the proportion of the output in Agricultural Sciences has increased in most of the former Soviet countries, with Latvia seeing the largest increase by seven percentage points, followed by Uzbekistan, Lithuania, Kazakhstan, and Estonia (Fig. 13).

The absolute majority of the publications from post-Soviet countries are co-authored. The same applies to world output, as seen in Fig. 4. Co-authored publications include smaller co-authorships of two to five individuals, larger co-authorships of six to twenty individuals, and mega-collaborations with $21+$ authors. The most popular form of authorship (ranging between 48 and $66 \%$ of all publications) across post-Soviet countries is small teams of two to five. Larger co-authorships constitute 14 to $36 \%$ of all publications. All countries included in the analysis have a larger share of mega-collaborations than the world average of $0.4 \%$ (Fig. 4). Armenia and Georgia are noteworthy in this regard as the $24 \%$ of research output from Armenia and $21 \%$ from Georgia are authored by mega teams of more than 21 researchers. Azerbaijan and Latvia have the next largest shares of mega-collaborations, one in ten publications.

Substantial proportions of co-authored publications emerge from international collaborations. The larger the number of authors, the more likely the publication is to have at least one author from another country (Fig. 5). International co-authorship is used in this study as a measure of international collaboration, adopting the most widely used measure of collaboration that originates from Melin and Persson (1996). Almost all publications from post-Soviet countries with $21+$ authors have at least one international collaborator. The practice of international co-authorship is markedly more widespread in this region than globally (Figs. 5, 6). 


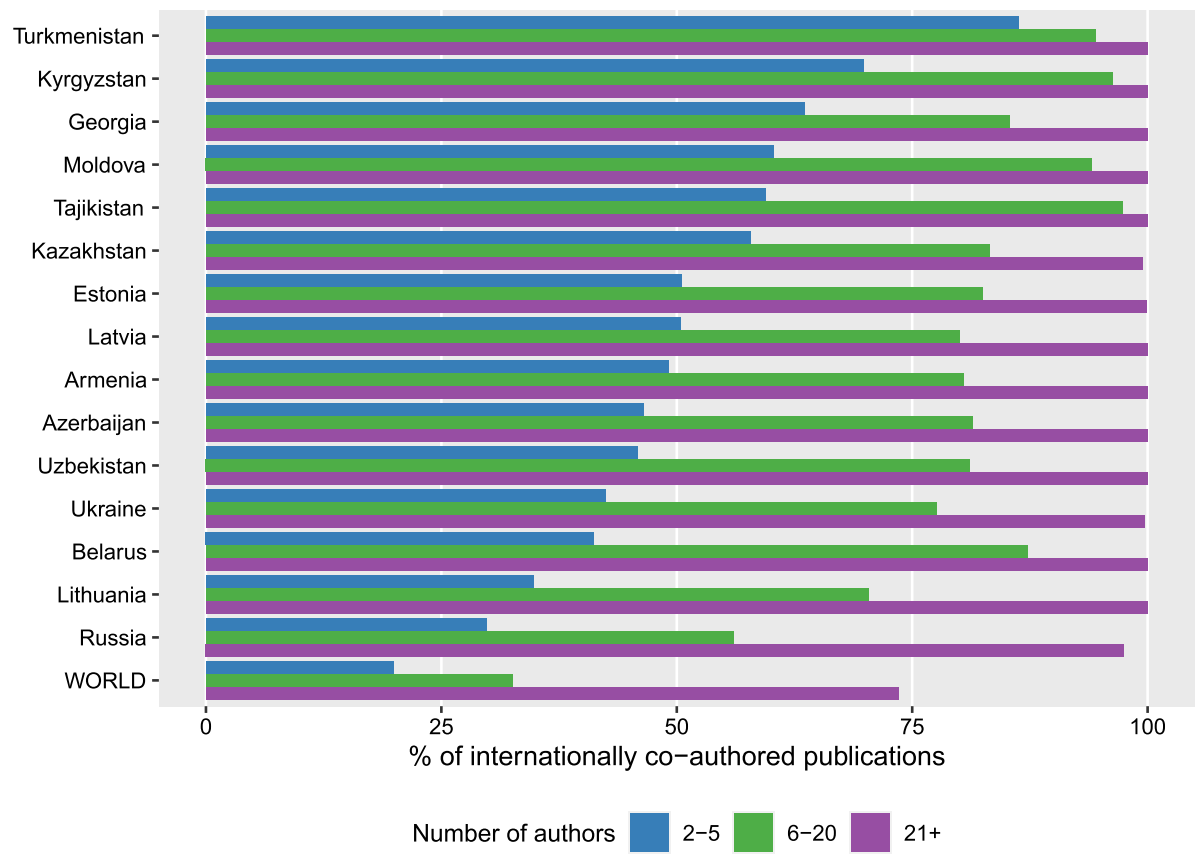

Fig. 5 Proportions of internationally co-authored publications among publications with different number of authors (1993-2019)

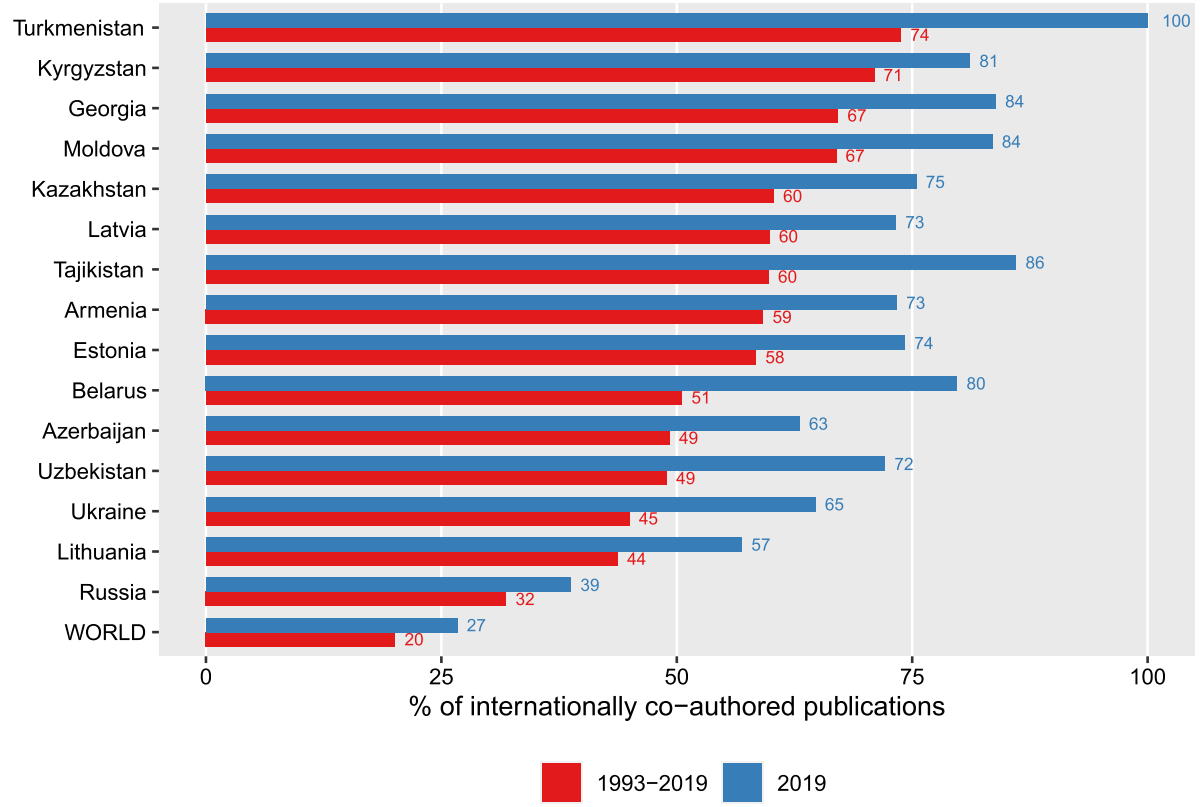

Fig. 6 Proportions of Internationally Co-Authored Publications (1993 - 2019) 
In 1993 - 2019, every post-Soviet country had a higher proportion of internationally coauthored publications than the world average of $20 \%$ (Fig. 6). Three in ten publications produced by researchers from this region were internationally co-authored. Yet, the country-level variation is large. Turkmenistan, Kyrgyzstan, Georgia, and Moldova have about 7 in 10 publications co-authored internationally (Fig. 6). These are followed by Kazakhstan, Latvia, Tajikistan, Armenia, and Estonia, with about 6 in 10 publications with international co-authors. Russia has the lowest proportion of internationally co-authored publicationsless than one in three-but still above the world average of one in five.

Figure 6 also shows that these countries have been expanding their practices of international collaborations. The proportions of internationally co-authored publications are considerably larger in 2019 than for the period of 1993-2019. The increase in almost all of the former Soviet countries is much larger than the seven percentage point increase in international collaborations for the same period globally. The single country where the increase in the proportion of internationally co-authored publications is relatively small, and equals the global statistic, is Russia. There are three possible explanations for this. First, researchers in Russia may be less likely to seek collaborations abroad due to the large number of R\&D personnel at home (Table 1). Our analysis shows that post-Soviet countries with more R\&D personnel tend to have smaller proportions of internationally co-authored publications (Pearson's product-moment correlation $=-0.78, p<0.001$ ). The numbers of R\&D personnel are positively correlated with the GERD per researcher (Pearson's product-moment correlation $=0.74, p=0.002$ ); this observation leads to the second potential explanation of Russia's relatively low engagement in international research collaborations. With the highest GERD per researcher in the region (Table 1), Russian scholars may be less likely to seek international collaborations for the purpose of accessing international research funding. It is recognised that access to research funding can be a potent driver for international collaborations (Jeong et al., 2014; Kwiek, 2017). Finally, there exist Russia-based journals where Russian scholars publish (Alimova \& Brumshteyn, 2020); these are in English and in Russian, in almost all major disciplines. More than 150 of them are indexed in WoS; this is several times more than the number of WoS-indexed journals from other post-Soviet countries. In these 'local' journals co-authors from outside Russia are rather rare. Being indexed in WoS, these journals/publications add to the denominator when we calculate the percentage of international co-authorship. If we remove Russia-based journals from 2019 statistics, the proportion of international collaborations of Russian authors increases from 38.7 to $56.3 \%$.

\section{Quality of journals}

This study measures the quality of journals by the quartile ranking of journals in which outputs are published. Our analysis shows that while the differences by country are large, taken together, publications from the region are of considerably lower quality than the world average (Fig. 7). In the period of 1993-2019, 43\% of the global research output appeared in Q1 journals. This is a significantly larger proportion than the average for postSoviet countries (23\%). Estonia has produced the highest proportion of high quality and the lowest proportion of lower quality output. In contrast, Tajikistan appears to have the lowest proportion of Q1 publications and the largest share of Q4 publications. Approximately 45\% of all publications from Tajikistan and Russia are published in the lowest impact factor journals. The former Soviet countries with smaller proportions of publications in Q1 journals tend to have larger shares of publications in Q4 journals (Fig. 7). 


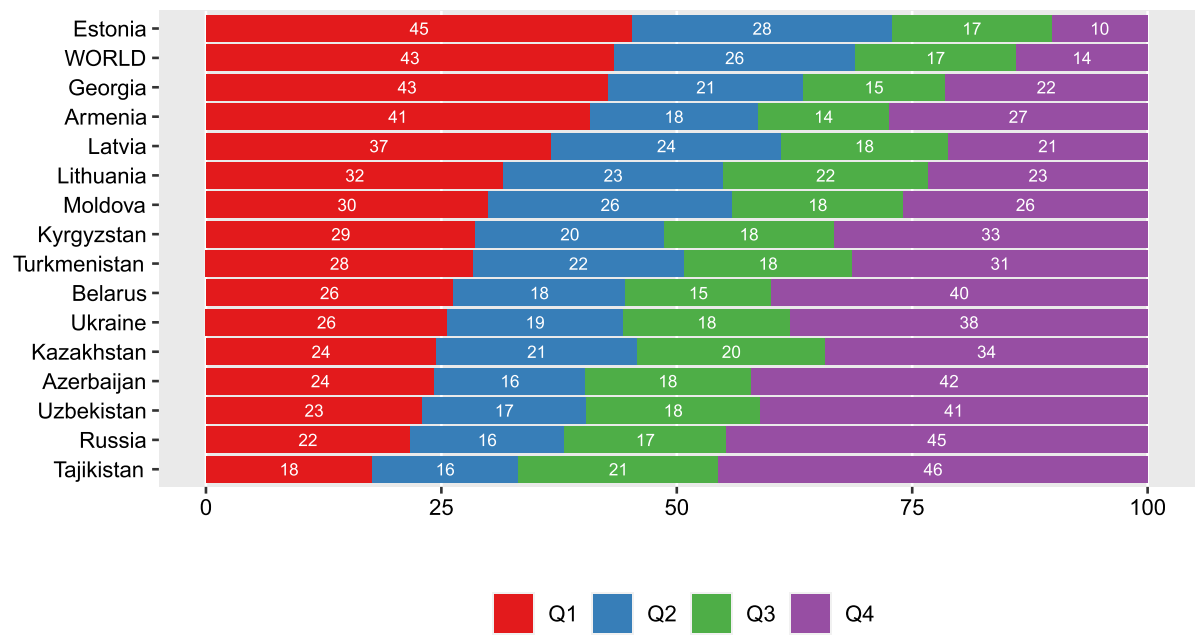

Fig. 7 Proportions of publications in Q1-Q4 journals (1993 - 2019)

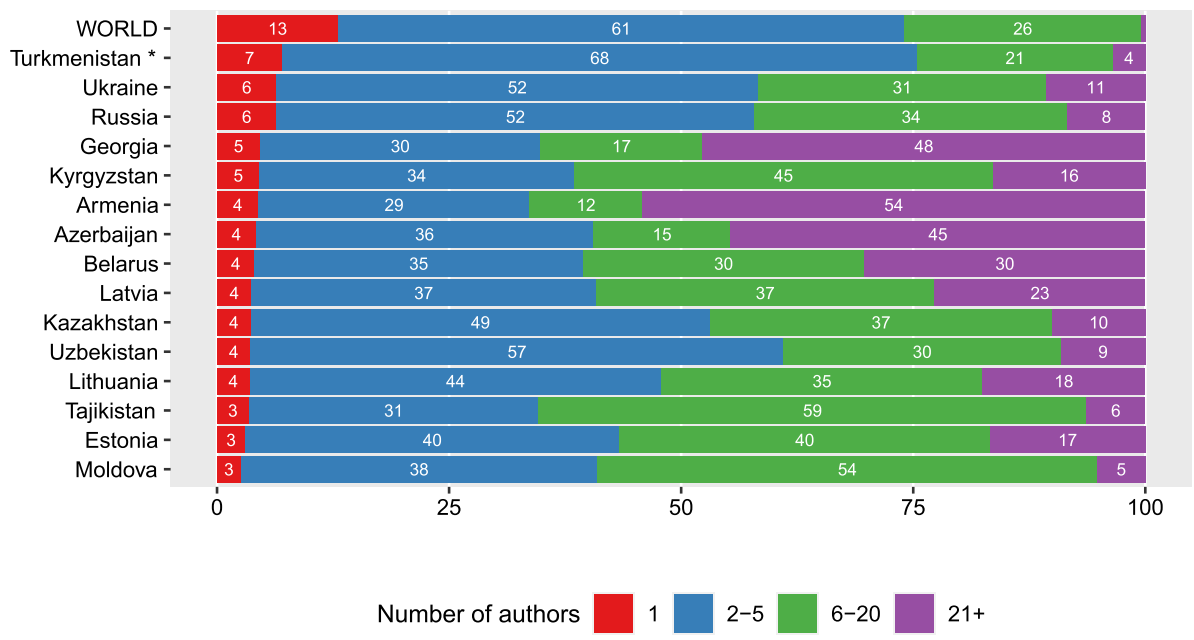

Fig. 8 Proportions of publications with different number of authors among publications in Q1 journals (1993-2019). Note: Countries with asterisks have fewer than 200 papers

As seen in Fig. 7, Georgia and Armenia have produced exceptionally high quality output and are closest to the world average with more than four in ten publications in Q1 journals. At the same time, these two countries have large proportions of relatively low quality research output, unlike Estonia. One way to explain the high proportions of Q1 publications from Armenia and Georgia is to look at the authorship patterns of output published in Q1 journals (Fig. 8). The publications with larger numbers of authors are more likely to be found in Q1 journals than publications with fewer authors across all post-Soviet countries. The fact that some countries, notably Armenia and Georgia, have larger proportions of papers emerging from mega-collaborations than other countries 
(Fig. 4) can offer one possible explanation for the relatively high representation of their output in Q1 journals. In contrast, single-authored papers are less likely to be found in Q1 journals (Fig. 8). Tajikistan, Russia, and Azerbaijan have large proportions of single-authored output (Fig. 4) and are relatively overrepresented in Q4 journals (Fig. 7). As for Russia, this effect is also largely explained by publishing in 'national' Russianlanguage journals which were mentioned before. These journals, due to their relative isolation, often have low impact factors.

The examination of the quality of output by area of study (Fig. 14) adds more nuance to the broader patterns presented in Fig. 7. Since the majority of the publications from post-Soviet countries are in Natural Sciences (Fig. 3), the distribution of Natural Science publications in Q1 to Q4 journals closely resembles the distribution of publications in all areas of study taken together (Fig. 7). Estonia, Georgia, and Armenia have particularly large proportions of Natural Science publications in Q1 journals, while Tajikistan, Russia, and Uzbekistan have the smallest proportions of Natural Science publications in Q1 journals (Fig. 14).

While Engineering \& Technology takes up a large share of publications from this region $(22 \%)$, the quality of the output appears to be below the world average. An unusual pattern was detected here in terms of the discrepancy between the interest in the area and the quality of output. Two countries with the strong interest in this area-Ukraine and Belarus-with almost one in three publications in Engineering \& Technology (Fig. 3), have one-third of their Engineering and Technology publications in the lowest quartile journals (Fig. 14). The leader in producing the largest proportion of Engineering and Technology publications in Q1 journals is Estonia. Turkmenistan comes second, however it has only 34 publications on Engineering and Technology, so the results may not be reliable.

In Medical \& Health Sciences, Estonia produces the largest proportion (45\%) of top quality publications and has the largest proportion of Medical \& Health Science publications as a share of all publications (Fig. 3). The largest increase in Medical \& Health Science publications took place in Kyrgyzstan and Moldova. These two countries follow Estonia with four in ten publications in top journals. In contrast, Uzbekistan and Turkmenistan have the smallest proportions of Medical \& Health Sciences publications in Q1 journals (Fig. 14).

In Social Sciences, Georgia has the largest proportion (40\%) of Q1 publications. This is followed by Armenia with $36 \%$ of publications in Q1 journals. In contrast, Turkmenistan has no Q1 publications in Social Sciences, followed by Ukraine and Russia with only 14 and $17 \%$ of all their Social Sciences publications in top journals. Ukraine and Russia also have substantial shares of Social Sciences publications in Q4 journals-60\% and 54\%-respectively (Fig. 14).

Estonia is the leader in Agricultural Sciences with 55\% of all publications in this area published in top journals. Latvia, Uzbekistan, and Turkmenistan have about four in ten of their publications in Agricultural Sciences published in Q1 journals. While Russia and Belarus have the largest proportions of the lowest quality output, Azerbaijan has the smallest proportion (17\%) of publications in Q1 journals.

Finally, the analysis of the spending on R\&D and the quality of output shows that none of the three measures of spending (GERD as \% of GDP, GERD per researcher, or GERD per capita) are linked to the proportions of papers published in any of the four quartiles. In other words, based on the latest country-level data from post-Soviet countries, the spending on research cannot be directly linked to the quality of the output. 


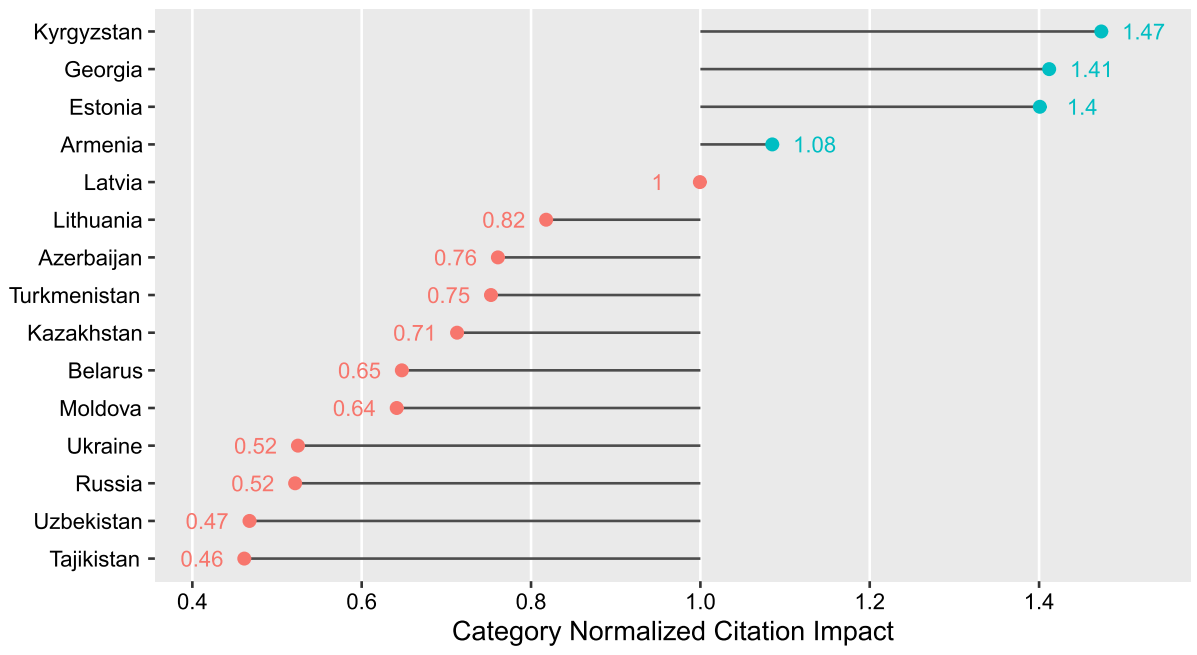

Fig. 9 Category normalised citation impact (1993-2019), with value 1 as the world average

\section{Impact}

The number of times each publication is cited is used as an indicator of impact of research output. We use the following two indicators: Category Normalized Citation Impact (CNCI) and the proportion of publications in the Top $10 \%$ of the most cited publications in the InCites database. Both indicators are normalized by area of study, year of publication, and publication type. These two indicators complement each other as CNCI is calculated as an average, while the Top $10 \%$ is based on the ranking. In the 1993 - 2019 data, there is a very high correlation between the two indicators (Pearson's product-moment correlation $r=0.86, p=0.001$ ). Moreover, both impact indicators are highly correlated with the journal quality indicators, in particular with the proportions of publications in Q1 and Q4 journals. Countries with higher CNCI/higher proportions of papers in the Top $10 \%$ have significantly larger proportions of publications in Q1 journals and significantly lower proportions of publications in Q4 journals.

The CNCI of publications from the majority of post-Soviet countries has been going up over the last three decades, and specifically in the last decade (Fig. 15). Yet, the average impact of publications for 1993-2019 from the majority of post-Soviet countries is below the world average for the same period (Fig. 9). The publications from four countries-Kyrgyzstan, Estonia, Georgia, and Armenia—have impact ratings higher than the world average of one. While Armenia, Estonia, and Georgia show a steady increase in the CNCI, Kyrgyzstan had larger spikes in CNCI in 2017, which is driven by a dozen of papers written by mega medical collaborations (Fig. 17).

The publications from Tajikistan, Uzbekistan, Russia, and Ukraine have particularly low impact ratings when compared to the world average. There could be three possible reasons for this: large proportions of researchers choose relatively low quality journals, there exists a mistrust of the research from non-leading countries which is known as the Matthew effect (Pislyakov \& Dyachenko, 2010), and/or relatively poor quality of research produced in these countries. 


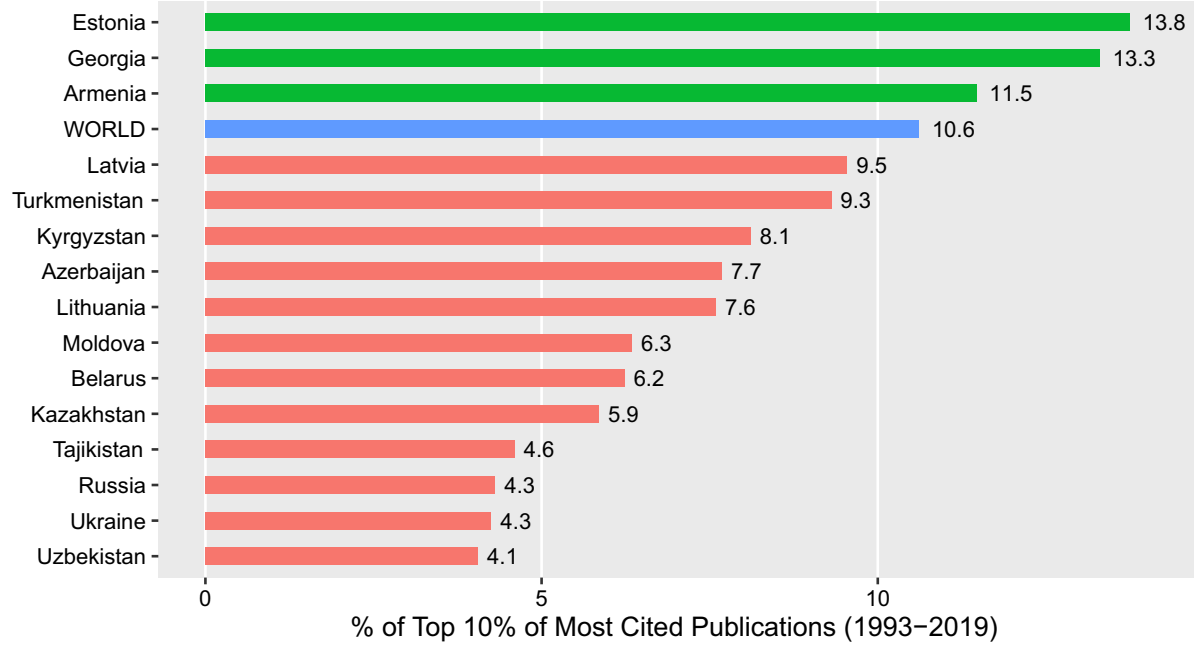

Fig. 10 Proportions of top10\% most cited publications (1993 - 2019)

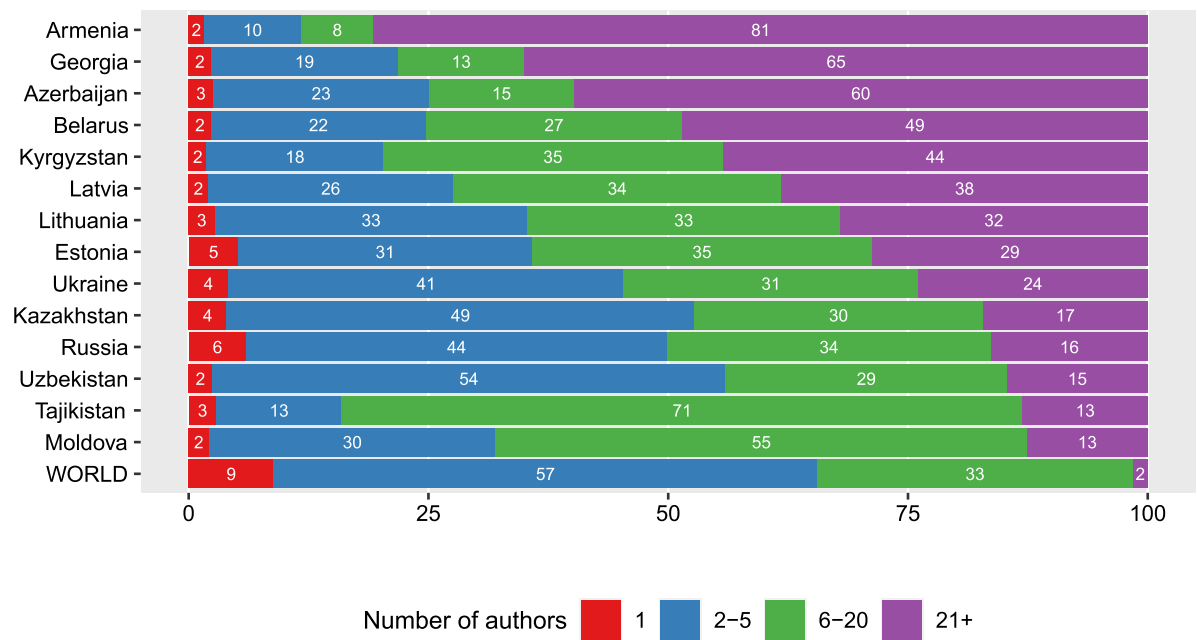

Fig. 11 Proportions of top10\% most cited publications, by number of authors (1993 - 2019)

Another indicator of impact is the proportion of publications included in the world's Top10\% most cited publications. As seen in Fig. 10, a small group of post-Soviet countries-Estonia, Georgia, and Armenia-have been over performing in terms of having more than $10 \%$ of their publications in the world's Top $10 \%$ most impactful publications. While Estonia had a relatively steady increase in the proportion of publications in the Top10\%, Armenian and Georgian statistics show more fluctuation. For the latter, the major increase in the proportion of the Top $10 \%$ most cited publications started in 2010 (Fig. 18).

One possible explanation for the overrepresentation of publications from Armenia and Georgia in the Top $10 \%$ most cited publications globally can be the exceptionally high 
proportions of $21+$ authored mega-collaborations in these countries (Fig. 4). The examination of the authorship patterns shows that very large shares of the Top $10 \%$ most impactful publications from the region have $21+$ authors, in contrast to the world average of two percent (Fig. 11). Eighty-one percent of the most impactful publications from Armenia and sixty-five percent from Georgia are mega-collaborations. At the same time, single-authored papers from the majority of post-Soviet countries are unlikely to be in the Top $10 \%$ of most cited publications. The exceptions are Russia and Estonia that have relatively larger proportions of high-impact single-authored publications (Fig. 11).

Co-authored publications often emerge from international collaborations (Fig. 5). Globally, internationally co-authored publications tend to be more cited and have higher impact than domestically co-authored publications (Adams, 2013; Bordons et al., 2015; Glänzel, 2001; Olechnicka et al., 2017). For example, Hirv (2019) examines the Estonian case of having a large proportion of high impact publications. The study explains the phenomenon of mega-collaborations in physics or in medicine/epidemiology where some papers have hundreds or even thousands of authors. These papers are expected to be actively cited and have a high impact. The impact of such publications can greatly affect the overall indicators of countries, especially if the country has a small total number of papers (Hirv, 2019). In another study, Pislyakov and Shukshina (2014) explore the Top 1\% of highly cited papers from Russia to find that $92 \%$ of these involve international partnership. The average proportion of Russian addresses among all authors' affiliations in such publications is only about $33 \%$.

Across post-Soviet countries, the highest impact publications (based on CNCI) are produced in Medical \& Health Sciences, Humanities and Natural Sciences (Fig. 16). In Social Sciences, only Georgian publications have an impact higher than one. In Agricultural Sciences, Estonian and Ukrainian publications have an impact higher than one. The lowest impact publications are produced in Engineering \& Technology (Fig. 16). Similar results are observed with the Top $10 \%$ indicator (Fig. 18). The overall similarity in the findings based on these two different indicators-CNCI and Top10\%—confirms the robustness of the results.

Finally, the spending on R\&D (GERD as \% of GDP, GERD per researcher, or GERD per capita) cannot be directly associated with either of the measures of impact (CNCI, Top 10\%).

\section{Discussion and conclusions}

There has been some criticism of bibliometric methods, arguing that such analyses further disadvantage peripheral countries and reinforce asymmetries in the process of global knowledge creation (Hountondji, 2006; Martinez \& Sá, 2020; Velho, 1986). While we recognise the unequal footing of many researchers and research institutions from this region, this study has offered some empirical evidence on the existence of large variations within this region. The big picture analysis of the quantity and impact of the output and the quality of journals by area of study, by authorship, and by country demonstrated that post-Soviet countries differ considerably in terms of how much they have prioritised research, the amount of research output each country has produced, as well as the quality and impact of the output.

The former Soviet countries are not key players on the global research scene, as they cumulatively produce about three percent of the global output included in the WoS 
database. This is comparable to the cumulative research output from all countries on the African continent. The countries in Latin America have a slightly larger share (5\%) of publications in the global domain. In contrast, the USA and China each produce $24 \%$ of the global research output.

Russia is the regional leader when it comes to the quantity of WoS publications, largely due to the size of its higher education and research system. Russian researchers produce $76 \%$ of the output analysed in this study. At the same time, very large proportions of Russian WoS publications are of lower quality and lower impact when compared with other post-Soviet countries-Russian WoS publications are second from the bottom in terms of the quality of journals and third from the bottom in terms of publication impact.

Rich scientific traditions in Natural Sciences and to a certain extent in Engineering \& Technology must have contributed to the popularity of these areas of study across all postSoviet countries. Yet, in the last two decades, the interest in Natural Sciences and Engineering and Technology has been dropping in a number of these countries. Meanwhile, the popularity of Medical \& Health Sciences, Agricultural Sciences, and Humanities has been increasing slowly but steadily in most countries. Researchers in some countries appear to have been paving new paths in Social Sciences, Humanities, and Agricultural Sciences, the areas of studies where these countries had very small proportions of publications in the 1990s.

While the differences between countries are large, the research productivity across the region has not been high and post-Soviet countries' cumulative contribution to global knowledge creation has been of considerably lower quality when viewed in the context of the quality of global research output. Estonia has the largest proportion of publications in top journals, followed by Georgia and Armenia. This is predominantly driven by the output in Natural Sciences that dominates the research output across all post-Soviet countries. As such, Estonia, Georgia, and Armenia have the highest shares of top quality output in Natural Sciences. Furthermore, Georgia and Armenia produce the largest share of top quality Social Sciences publications when compared to other post-Soviet countries. Estonia has the largest proportion of top quality publications in Medical \& Health Sciences, Engineering \& Technology, and Agricultural Sciences.

The impact of publications from many post-Soviet countries has been going up in the last three decades, and specifically in the last decade. Yet, the average impact of publications for 1993-2019 from the majority of the former Soviet countries is below the world average for the same period. In contrast to the evidence of a journal's impact factor being a poor predictor of a particular paper's citations (Seglen, 1997; Stringer et al., 2008; Wang et al., 2013), post-Soviet countries with larger shares of papers in Q1 journals and lower proportions of papers in Q4 journals, tend to have significantly higher proportions of high impact papers. This study suggests that one way to explain the relatively high impact of publications from selected countries is to look at international collaborations, and in particular mega-collaborations.

Across all countries, publications with $21+$ authors are overrepresented in the top quality journals and in the Top $10 \%$ of most cited output. Single-authored publications are less likely to be found in top journals and unlikely to be in the Top $10 \%$ of most cited publications. Large proportions of co-authored publications emerge from international collaborations.

The findings of this study suggest that researchers in post-Soviet countries tap into international collaborative networks actively. The role of international collaborations in increasing the research productivity has been documented in the literature on other geographical contexts, including the African countries (Skupien, 2019). The practice of 
international co-authorship is much more widespread in this region than globally where only one in five publications are internationally co-authored. In contrast, in twelve out of fifteen former Soviet countries, $50 \%$ or more of the publications are internationally co-authored. $70 \%$ of publications from Turkmenistan, Kyrgyzstan, Georgia, and Moldova are the result of international collaborations. Extensive international collaborations, as expressed by international co-authorships, may indicate that these countries have researchers who are attractive to international collaborators, to follow the logic of Wagner and Leydesdorff (2005). The latter propose that science is a self-organising system and that 'the spectacular growth in international collaborations may be due more to the dynamics created by the self-interests of individual scientists rather than to other structural, institutional or policy-related factors that have been suggested by others' (p.1616). The self-interests of individual researchers can be driven by 'rewards, reputation, and resources offered by a collaborative network' (p. 1610). At the same time, the extensive collaborations may indicate a relatively modest capacity in these countries as researchers are inclined to seek resources internationally (Jeong et al., 2014; Kwiek, 2017). One thing is certain-this finding is also a demonstration of the integration of researchers and institutions producing research into global networks and needs to be viewed in the historical context of the Soviet research being known as one of the least collaborative globally (Schubert \& Braun, 1990).

Research productivity and research funding are arguably correlated (Powell \& Dusdal, 2017) and high-quality research is considered to be a privilege for rich countries (Allik, 2013). This study cannot fully confirm these assertions. We have shown that post-Soviet countries that spend more per researcher have larger numbers of researchers. More researchers tend to produce more publications. And the spending per researcher is linked with the countries' investment in R\&D as a percentage of GDP. Thus, countries that prioritize research, have more researchers and more publications. Yet, this is where the links between the characteristics of the output and the research funding end. This study found that none of the three measures of the national spending on research (GERD as \% of GDP, GERD per researcher, or GERD per capita) are linked with the quality or impact of the research output.

Thus, this study represents the first step in mapping the research output across postSoviet countries to confirm that, while the output may be modest, in the last thirty years, researchers in the majority of the post-Soviet countries have continued engaging in research and contributing to the global knowledge creation. Future studies on potential determinants of the differences highlighted here will need to examine the research output in relation to the variations in the national policies, institutional practices, and the individual expertise, motivation, and opportunity.

\section{Appendix}

See Figs. 12, 13, 14, 15, 16, 17 and 18. 

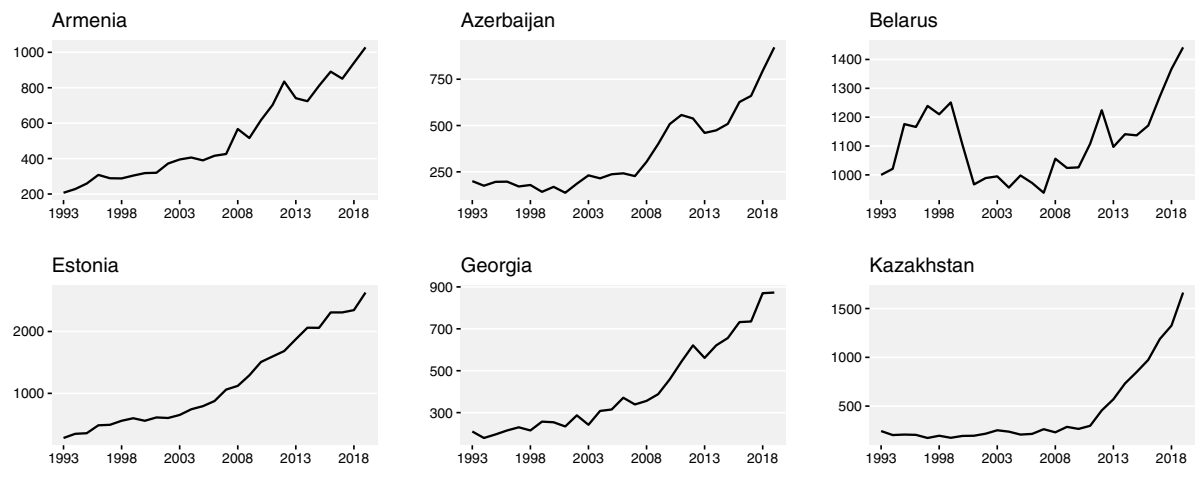

\section{Kazakhstan}
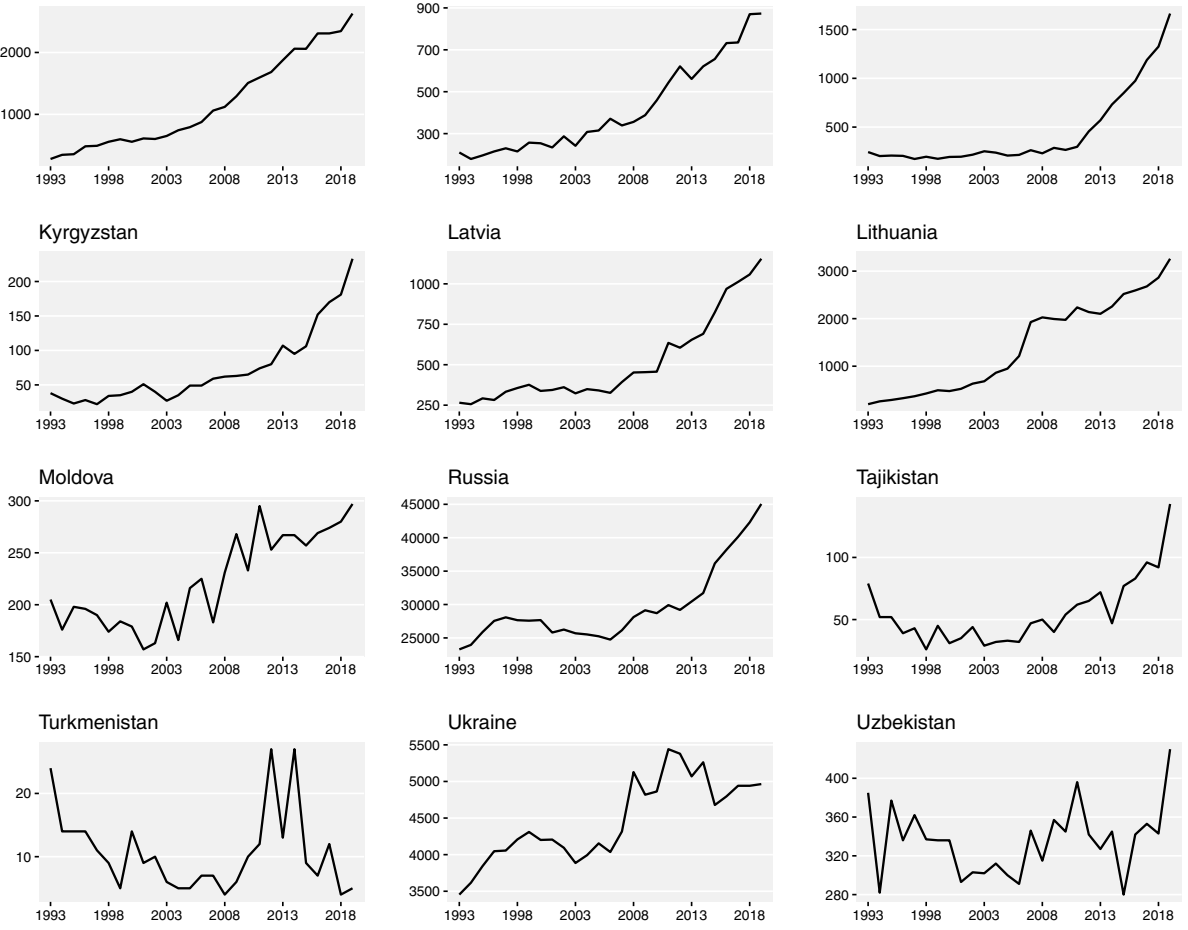

Fig. 12 Publishing trends, by year and by country 

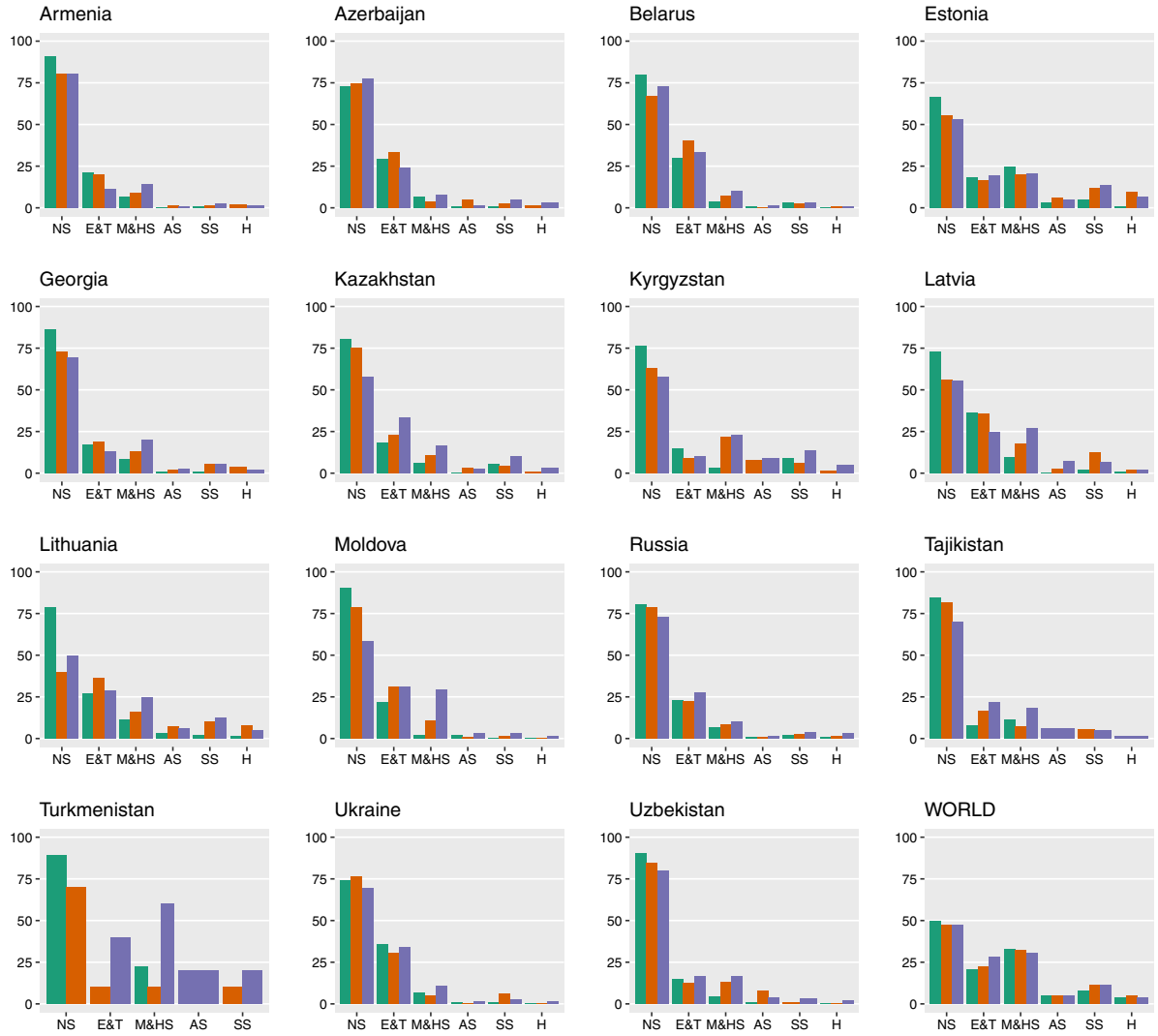

$1998 \square 2010 \square 2019$

Fig. 13 Distribution of publications by area of study in 1998, 2010, and 2018 

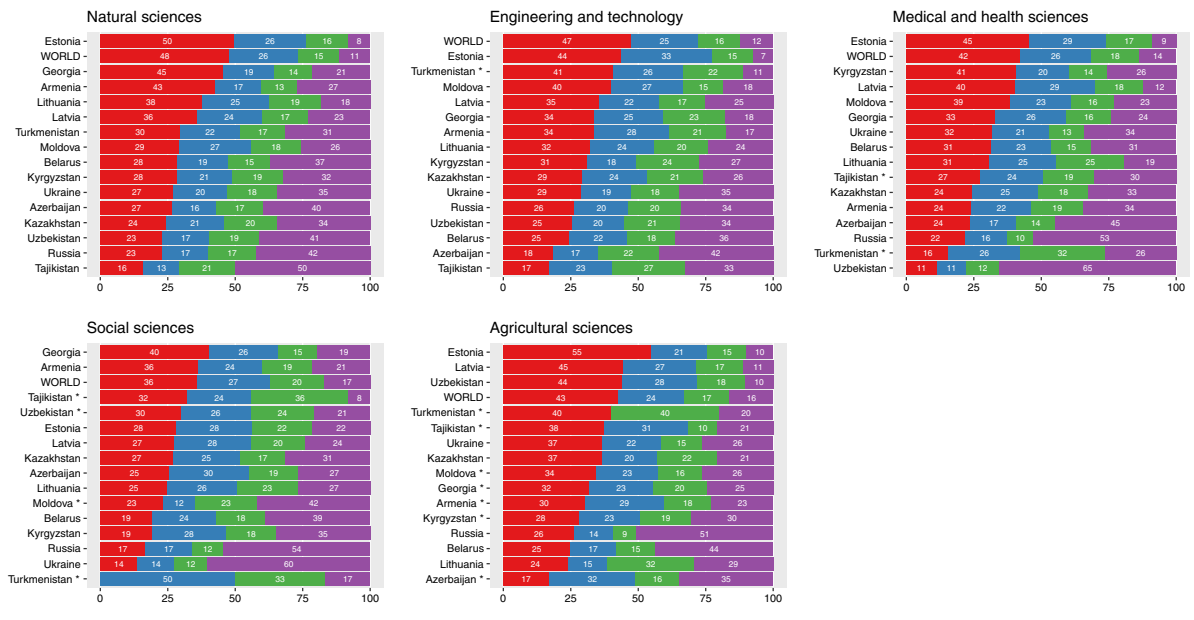

Agricultural sciences

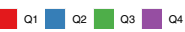

Fig. 14 Proportions (\%) of publications in Q1-Q4 journals (1993-2019), by area of study. Notes: (a) Humanities are not included because of the reason explained in the Data and Method section of this paper, (b) countries with asterisks have fewer than 200 articles in the area of study 

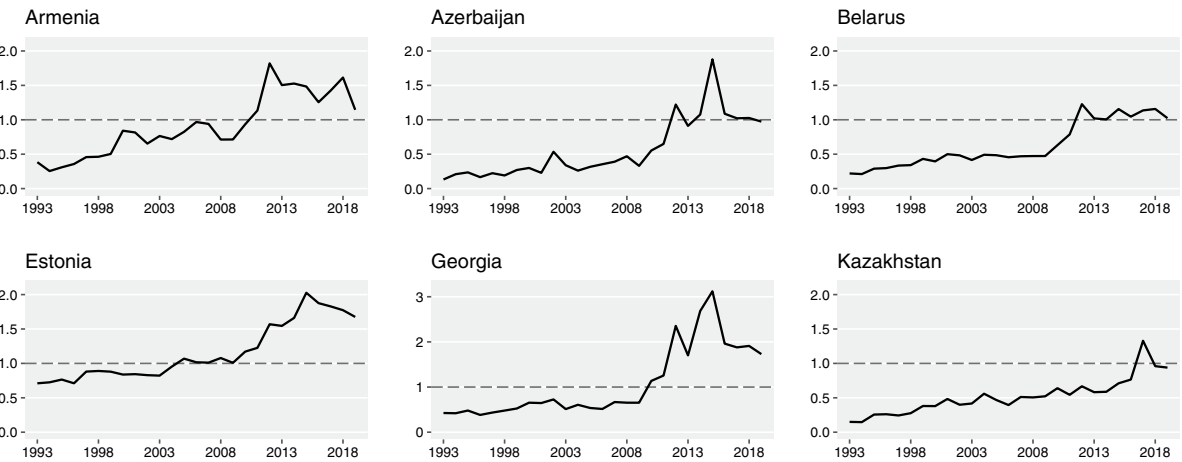

\section{Kazakhstan}

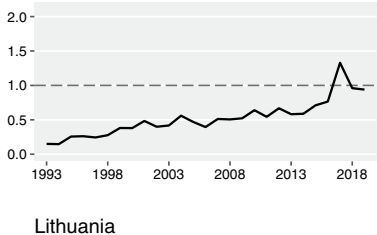

Kyrgyzstan
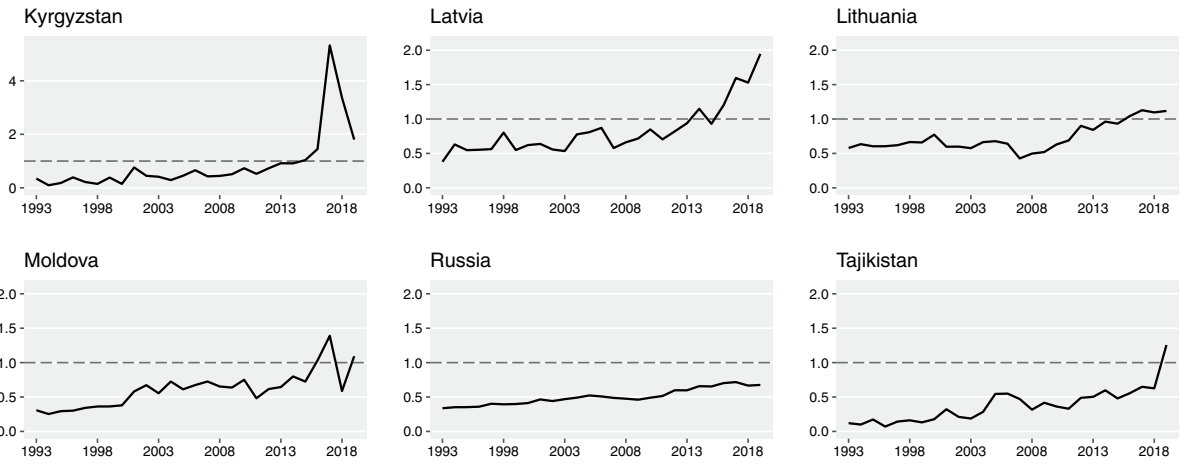

$$
\text { Russia }
$$

\section{Tajikistan}
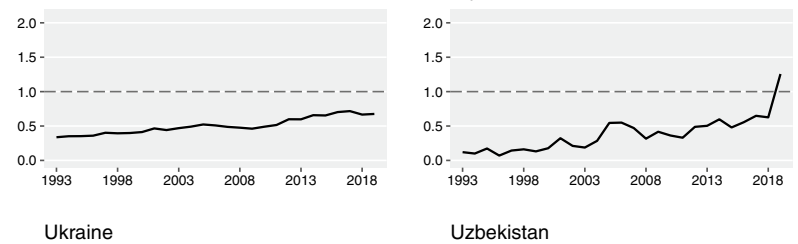

Turkmenistan
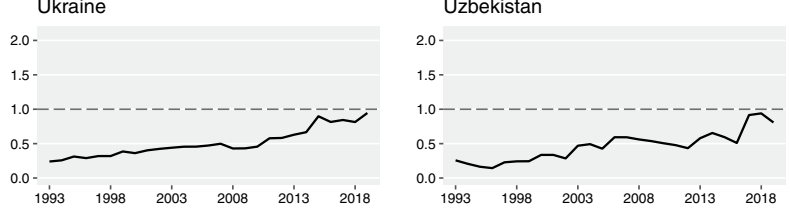

Fig. 15 CNCI trends, by year and by country 

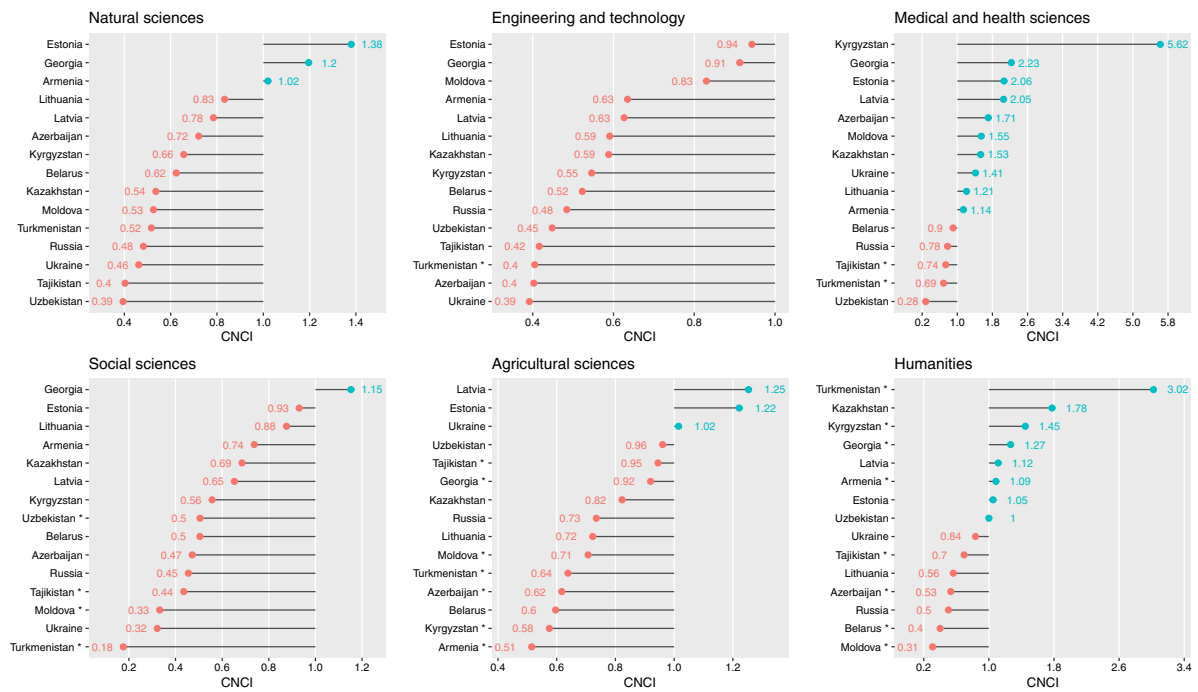

Fig. 16 CNCI by area of study. Note: countries with asterisks have fewer than 200 articles in the area of study 

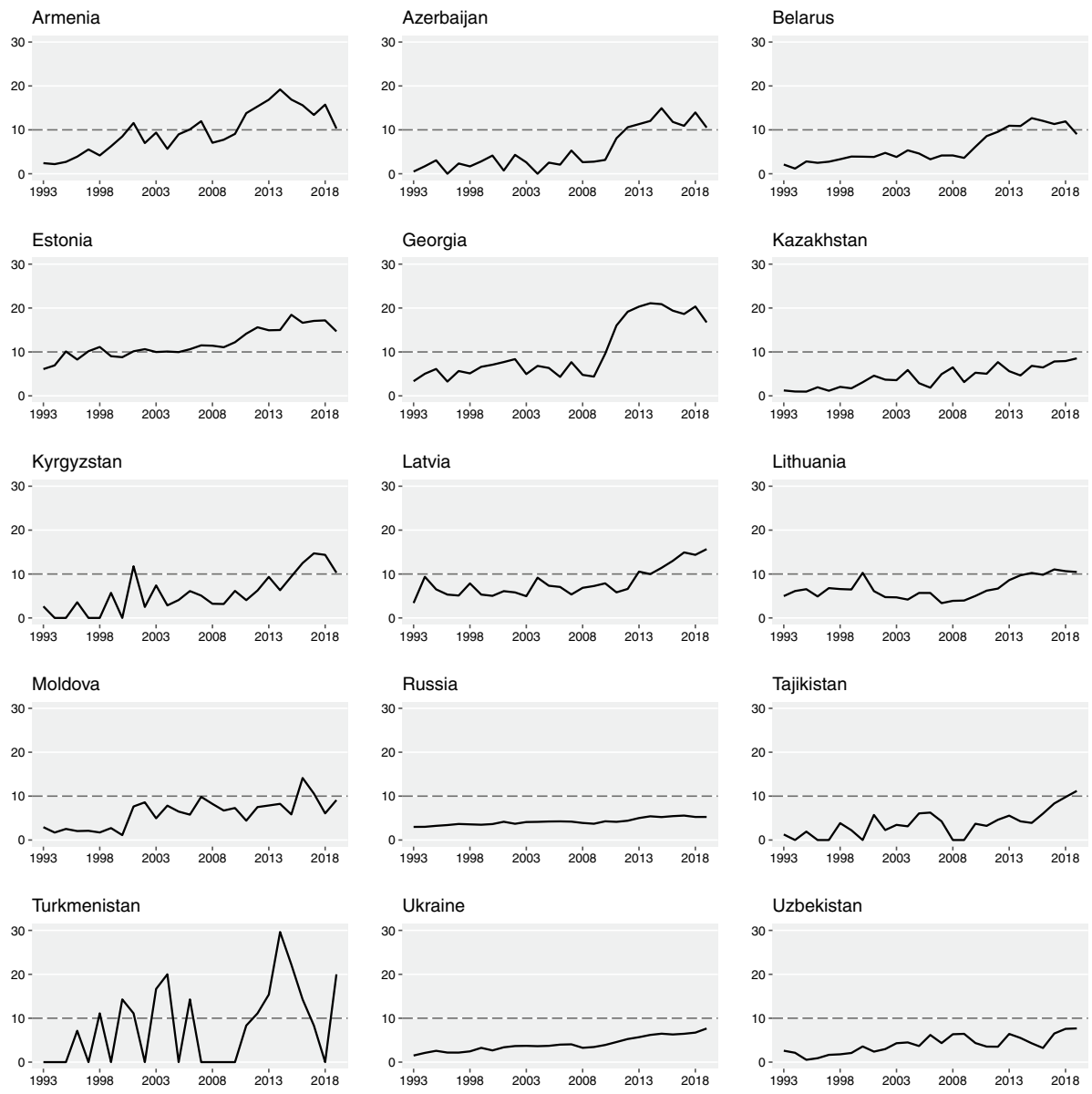

Fig. 17 The top $10 \%$ of most cited publications trends, by year and by country 

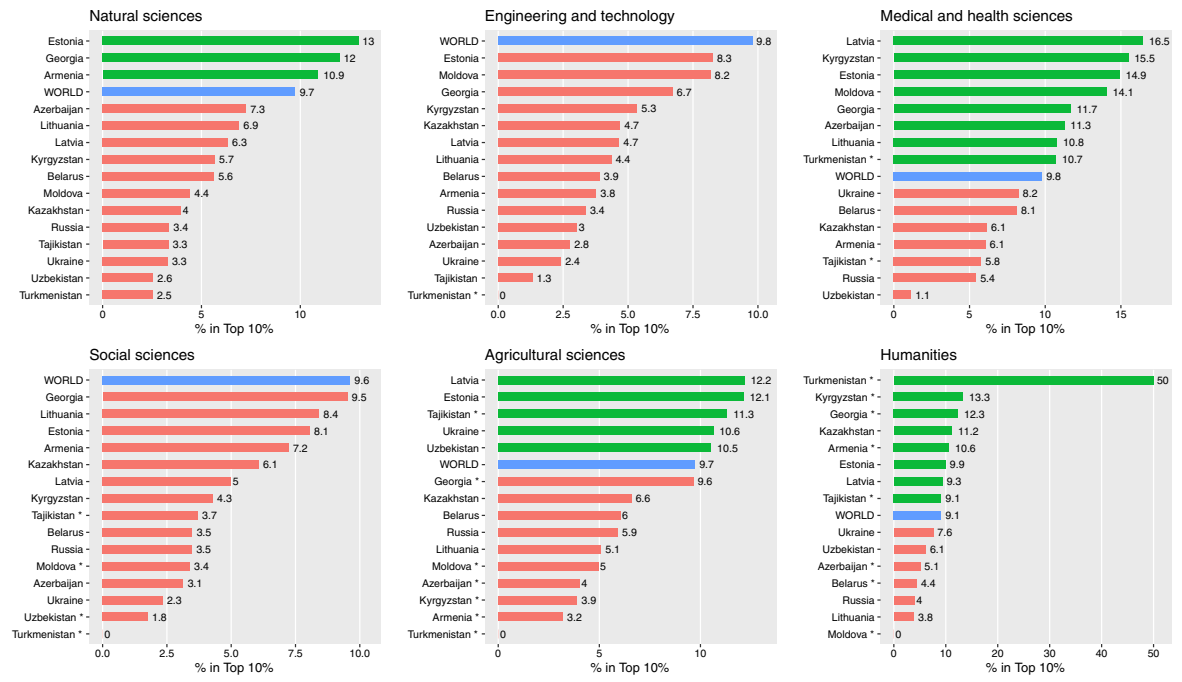

Fig. 18 Top $10 \%$ of most cited publications, by area of study. Note: countries with asterisks have fewer than 200 articles in the area of study

Acknowledgements The authors would like to thank Justin J W Powell and Peter Brookes for reading and providing feedback on the manuscript. Andrey Lovakov and Vladimir Pislyakov were supported by the Russian Science Foundation (grant 20-18-00140).

Open Access This article is licensed under a Creative Commons Attribution 4.0 International License, which permits use, sharing, adaptation, distribution and reproduction in any medium or format, as long as you give appropriate credit to the original author(s) and the source, provide a link to the Creative Commons licence, and indicate if changes were made. The images or other third party material in this article are included in the article's Creative Commons licence, unless indicated otherwise in a credit line to the material. If material is not included in the article's Creative Commons licence and your intended use is not permitted by statutory regulation or exceeds the permitted use, you will need to obtain permission directly from the copyright holder. To view a copy of this licence, visit http://creativecommons.org/licenses/by/4.0/.

\section{References}

Adambekov, S., Askarova, S., Welburn, S. C., Goughnour, S. L., Konishi, A., LaPorte, R., \& Linkov, F. (2016). Publication productivity in Central Asia and Countries of the former Soviet Union. Central Asian Journal of Global Health, 5(1), 261. https://doi.org/10.5195/cajgh.2016.261

Adams, J. (2013). The fourth age of research. Nature, 497(7451), 557-560.

Aksnes, D. W., \& Sivertsen, G. (2004). The effect of highly cited papers on national citation indicators. Scientometrics, 59(2), 213-224.

Aksnes, D. W., \& Sivertsen, G. (2019). A Criteria-based assessment of the coverage of scopus and web of science. Journal of Data and Information Science, 4(1), 1-21.

Alimova, N., \& Brumshteyn, Y. (2020). Russia and post-Soviet countries compared: Coverage of papers by Scopus and Web of Science, languages, and productivity of researchers. European Science Editing, 46, e53192.

Allik, J. (2008). Quality of Estonian science estimated through bibliometric indicators (1997-2007). Proceedings of the Estonian Academy of Sciences, 57(4), 255-264. https://doi.org/10.3176/proc. 2008.4.08

Allik, J. (2013). Factors affecting bibliometric indicators of scientific quality. Trames Journal of the Humanities and Social Sciences, 17(3). 
Allik, J. (2015). Progress in Estonian science. Proceedings of the Estonian Academy of Sciences, 64(2), 125-126.

Bordons, M., González-Albo, B., Aparicio, J., \& Moreno, L. (2015). The influence of R\&D intensity of countries on the impact of international collaborative research: Evidence from Spain. Scientometrics, 102(2), 1385-1400.

Brumshteyna, Y. M., \& Alimova, N. K. (2019). Scientific Journals in the post-Soviet States: The Place in the National and International Information Space. Russian Journal of Regional Studies, (4 (109)), $831-857$.

Chankseliani, M. (2018). The politics of student mobility: Links between outbound student flows and the democratic development of post-Soviet Eurasia. International Journal of Educational Development, 62, 281-288.

Chankseliani, M., \& Silova, I. (2018a). Reconfiguring Education purposes, policies, and practices during post-socialist transformations: Setting the stage. In M. Chankseliani \& I. Silova (Eds.), Comparing Post-Socialist Transformations: Purposes, Policies, and Practices in Education (pp. 7-25). Symposium Books.

Chankseliani, M., \& Silova, I. (Eds.). (2018b). Comparing Post-socialist transformations: Purposes, policies, and practices in education. Symposium Books.

Collyer, F. M. (2018). Global patterns in the publishing of academic knowledge: Global North, global South. Current Sociology, 66(1), 56-73.

Dickenson, R. P. (1996). The level of research in advanced composite materials in the countries of the former Soviet Union. Scientometrics, 36(1), 43-57. https://doi.org/10.1007/BF02126644

Fiala, D., \& Willett, P. (2015). Computer science in Eastern Europe 1989-2014: A bibliometric study. Aslib Journal of Information Management, 67(5), 526-541. https://doi.org/10.1108/AJIM-02-2015-0027

Gingras, Y. (2016). Bibliometrics and research evaluation: Uses and abuses. MIT Press.

Glänzel, W. (2001). National characteristics in international scientific co-authorship relations. Scientometrics, 51(1), 69-115.

Graham, L. R. (1992). Big Science in the last years of the big Soviet Union. Osiris, 7(1), 49-71.

Gzoyan, E. G., Hovhannisyan, L. A., Aleksanyan, S. A., Ghazaryan, N. A., Hunanyan, S. R., Bourghida, A., \& Sargsyan, S. A. (2015). Comparative analysis of the scientific output of Armenia Azerbaijan and Georgia. Scientometrics, 102(1), 195-212. https://doi.org/10.1007/s11192-014-1452-y

Hirv, T. (2019). Research consortia determine a significant part of the bibliometric visibility of Estonian science. Trames Journal of the Humanities and Social Sciences, 23(3).

Hountondji, P. J. (2006). Global knowledge: Imbalances and current tasks. In G. Neave (Ed.), Knowledge, power and dissent: Critical Perspectives on higher education and research in knowledge society (pp. 41-60). UNESCO Publishing.

Jeong, S., Choi, J. Y., \& Kim, J.-Y. (2014). On the drivers of international collaboration: The impact of informal communication, motivation, and research resources. Science and Public Policy, 41(4), 520-531.

Karaulova, M., Gök, A., Shackleton, O., \& Shapira, P. (2016). Science system path-dependencies and their influences: Nanotechnology research in Russia. Scientometrics, 107(2), 645-670. https://doi.org/10. 1007/s11192-016-1916-3

Kirchik, O., Gingras, Y., \& Larivière, V. (2012). Changes in publication languages and citation practices and their effect on the scientific impact of Russian science (1993-2010). Journal of the American Society for Information Science and Technology, 63(7), 1411-1419. https://doi.org/10.1002/asi.22642

Kojevnikov, A. (2002). The Great War, the Russian Civil War, and the invention of big science. Science in Context, 15(2), 239-275.

Kozak, M., Bornmann, L., \& Leydesdorff, L. (2015). How have the Eastern European countries of the former Warsaw Pact developed since 1990? A bibliometric study. Scientometrics, 102(2), 1101-1117.

Kristapsons, J., Martinson, H., \& Dagytė, I. (2003). Baltic R\&D systems in transition: past experiences and future prospects. Riga: Zinātne. https://www.vdu.lt/cris/handle/20.500.12259/55502. Accessed 30 June 2021

Kwiek, M. (2017). International research collaboration and international research orientation: Comparative Findings about European Academics. Journal of Studies in International Education, 22(2), 136-160.

Kwiek, M. (2020). What large-scale publication and citation data tell us about international research collaboration in Europe: Changing national patterns in global contexts. Studies in Higher Education, 1-21.

Kyvik, S., \& Larsen, I. M. (1997). The Exchange of knowledge: A Small country in the international research community. Science Communication, 18(3), 238-264.

Lauk, K., \& Allik, J. (2018). A puzzle of estonian science: How to explain unexpected rise of the scientific impact. Trames. Journal of the Humanities and Social Sciences, 22, 329. https://doi.org/10.3176/tr. 2018.4.01

Lewis, J. M. (2013). Academic governance: Disciplines and policy. Routledge. 
Lewis, J. M., Ross, S., \& Holden, T. (2012). The how and why of academic collaboration: Disciplinary differences and policy implications. Higher Education, 64(5), 693-708.

Liu, W. (2017). The changing role of non-English papers in scholarly communication: Evidence from Web of Science's three journal citation indexes. Learned Publishing, 30(2), 115-123.

Lovakov, A., \& Agadullina, E. (2019). Bibliometric analysis of publications from post-Soviet countries in psychological journals in 1992-2017. Scientometrics, 119(2), 1157-1171. https://doi.org/10.1007/ s11192-019-03087-y

Lovakov, A., \& Yudkevich, M. (2021). The post-Soviet publication landscape for higher education research. Higher Education, 81(2), 273-299. https://doi.org/10.1007/s10734-020-00541-2

Markusova, V. A., Jansz, M., Libkind, A. N., Libkind, I., \& Varshavsky, A. (2009). Trends in Russian research output in post-Soviet era. Scientometrics, 79(2), 249-260. https://doi.org/10.1007/ s11192-009-0416-0

Martinez, M., \& Sá, C. (2020). Highly Cited in the South: International Collaboration and research recognition among Brazil's highly cited researchers. Journal of Studies in International Education, 24(1), 39-58.

Matthews, M. (2011). Privilege in the Soviet Union: A Study of elite life-styles under communism. Routledge.

Melin, G., \& Persson, O. (1996). Studying research collaboration using co-authorships. Scientometrics, 36(3), 363-377.

Moed, H. F., Markusova, V., \& Akoev, M. (2018). Trends in Russian research output indexed in Scopus and Web of Science. Scientometrics, 116(2), 1153-1180.

Moskaleva, O., Pislyakov, V., Sterligov, I., Akoev, M., \& Shabanova, S. (2018). Russian index of science citation: Overview and review. Scientometrics, 116(1), 449-462. https://doi.org/10.1007/ s11192-018-2758-y

Muller, J. Z. (2018). The tyranny of metrics. Princeton University Press.

OECD. (2007). Revised Field of science and technology (FOS) classification in the Frascati manual. OECD. http://www.oecd.org/science/inno/38235147.pdf. Accessed 18 September 2020

Olechnicka, A., Ploszaj, A., \& Celinska-Janowicz, D. (2017). The geography of scientific collaboration (1st ed.). Routledge.

Pislyakov, V., \& Dyachenko, E. (2010). Citation expectations: Are they realized? Study of the Matthew index for Russian papers published abroad. Scientometrics, 83(3), 739-749.

Pislyakov, V., \& Shukshina, E. (2014). Measuring excellence in Russia: Highly cited papers, leading institutions, patterns of national and international collaboration. Journal of the Association for Information Science and Technology, 65(11), 2321-2330.

Potter, R. W. K., Szomszor, M., \& Adams, J. (2020). Interpreting CNCIs on a country-scale: The effect of domestic and international collaboration type. Journal of Informetrics, 14(4). http://www.scien cedirect.com/science/article/pii/S1751157720301188. Accessed 24 July 2020

Powell, J. J. W., \& Dusdal, J. (2017). Science Production in Germany, France, Belgium, and Luxembourg: Comparing the contributions of Research Universities and Institutes to Science, Technology, Engineering, Mathematics, and Health. Minerva, 55(4), 413-434.

Schneider, C. M. (2013). Research and Development management: From the Soviet Union to Russia. Springer Science \& Business Media.

Schubert, A., \& Braun, T. (1990). International collaboration in the sciences 1981-1985. Scientometrics, 19(1), 3-10.

Seglen, P. O. (1997). Why the impact factor of journals should not be used for evaluating research. $B M J$, 314(7079), 497.

Skupien, S. (2019). Searching for Macro-Meso-Micro-Level Links in Studies of North-South Research Collaborations. Minerva, 57(3), 391-410.

Stringer, M. J., Sales-Pardo, M., \& Amaral, L. A. N. (2008). Effectiveness of journal ranking schemes as a tool for locating information. PLOS ONE, 3(2), e1683.

Temkina, A., \& Zdravomyslova, E. (2003). Gender studies in post-Soviet society: Western frames and cultural differences. Studies in East European Thought, 55(1), 51-61.

Terekhov, A. I. (2017). Bibliometric spectroscopy of Russia's nanotechnology: 2000-2014. Scientometrics, 110(3), 1217-1242. https://doi.org/10.1007/s11192-016-2234-5

UIS. (2018). UNESCO Institute of statistics data. http://data.uis.unesco.org/index.aspx?queryid=74

UIS. (2020a). GERD per capita - definition. http://uis.unesco.org/en/glossary-term/gerd-capita. Accessed 15 July 2020

UIS. (2020b, June 22). Intramural R\&D expenditures-Definition. http://uis.unesco.org/en/glossaryterm/intramural-rd-expenditures. Accessed 15 July 2020 
USSR. (1988). National Economy of the USSR. Statistical yearbook [Народное хозяйство СССР. Статистический ежегодник]. http://istmat.info/node/17073. Accessed 20 October 2020

Velho, L. (1986). The "meaning" of citation in the context of a scientifically peripheral country. Scientometrics, 9(1-2), 71-89.

Wagner, C. S., \& Leydesdorff, L. (2005). Network structure, self-organization, and the growth of international collaboration in science. Research Policy, 34(10), 1608-1618.

Wang, D., Song, C., \& Barabási, A.-L. (2013). Quantifying Long-term scientific impact. Science, 342(6154), 127-132.

Weinberg, E. A. (2017). Sociology in the Soviet Union and beyond: Social Enquiry and Social Change. Routledge.

Wilson, C. S., \& Markusova, V. A. (2004). Changes in the scientific output of Russia from 1980 to 2000, as reflected in the Science citation index, in relation to national politico-economic changes. Scientometrics, 59(3), 345-389. https://doi.org/10.1023/B:SCIE.0000018539.93567.d8

World Bank. (2019). GDP per capita (current US\$). 2019 data. https://data.worldbank.org/indicator/NY. GDP.PCAP.CD. Accessed 9 May 2014

World Bank. (2020). Population, total I Data. https://data.worldbank.org/indicator/SP.POP.TOTL. Accessed 19 November 2018

Yegorov, I. (2009). Post-Soviet science: Difficulties in the transformation of the R\&D systems in Russia and Ukraine. Research Policy, 38(4), 600-609. https://doi.org/10.1016/j.respol.2009.01.010

Yessirkepov, M., Nurmashev, B., \& Anartayeva, M. (2015). A Scopus-based analysis of publication activity in Kazakhstan from 2010 to 2015: Positive Trends, concerns, and possible solutions. Journal of Korean Medical Science, 30(12), 1915-1919. https://doi.org/10.3346/jkms.2015.30.12.1915

Zavadskas, E., Kirvaitis, R., \& Dagienè, E. (2011). Scientific publications released in the Baltic States. Scientometrics, 88, 179-190. https://doi.org/10.1007/s11192-011-0394-x 